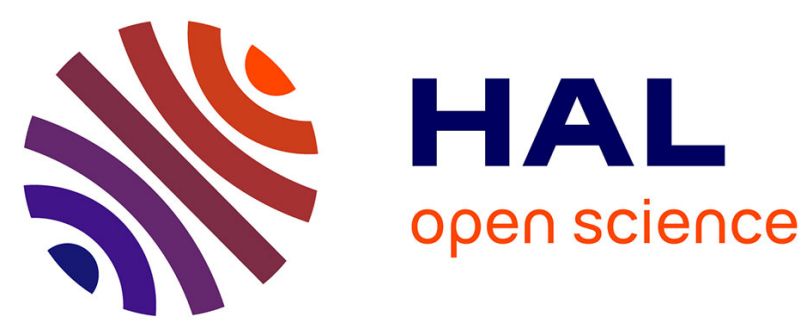

\title{
L'organisation spatiale de l'oppidum
}

Olivier Buchsenschutz, Roland Niaux, Dean Quinn, Jean-Loup Flouest, Daniele Vitali, Véronique Zwald, Hervé Richard, Katherine Gruel, Jean Gran-Aymerich, Miklós Szabó, et al.

\section{- To cite this version:}

Olivier Buchsenschutz, Roland Niaux, Dean Quinn, Jean-Loup Flouest, Daniele Vitali, et al.. L'organisation spatiale de l'oppidum. Gallia - Archéologie de la France antique, 1998, L'oppidum de Bibracte, 55, pp.18-48. 10.3406/galia.1998.3259 . hal-01308121

\section{HAL Id: hal-01308121 \\ https://hal.science/hal-01308121}

Submitted on 11 Mar 2020

HAL is a multi-disciplinary open access archive for the deposit and dissemination of scientific research documents, whether they are published or not. The documents may come from teaching and research institutions in France or abroad, or from public or private research centers.
L'archive ouverte pluridisciplinaire HAL, est destinée au dépôt et à la diffusion de documents scientifiques de niveau recherche, publiés ou non, émanant des établissements d'enseignement et de recherche français ou étrangers, des laboratoires publics ou privés.

\section{(ㅇ)(1) $\$$}

Distributed under a Creative Commons Attribution - NonCommercial - NoDerivatives| 4.0 
portail (III), un fournil (V et VI) et deux autres locaux jointifs (I et II), ils constituent les annexes agricoles.

Sous le couvent et ses annexes enfin, de nombreuses canalisations enterrées, constamment remaniées, prolongent des drains courant sous les sols : l'eau de la fontaine, située immédiatement en amont de la chapelle et alimentant le ruisseau de la Côme Chaudron, est ainsi captée pour assainir le terrain, fournir la communauté, évacuer ensuite les déchets domestiques de deux latrines (D et $\mathrm{ZA}$ ) vers une fosse septique flanquant à l'est les annexes d'exploitation (VII).

Plusieurs dizaines de monnaies des $\mathrm{XIV}^{\mathrm{e}}$-XVII ${ }^{\mathrm{e}}$ s. et un mobilier domestique abondant et diversifié, céramique, métallique, vitreux et ostéologique accompagnent les structures. Leur analyse, en cours, permettra d'identifier mieux encore les fonctions des différents locaux et d'éclairer l'environnement matériel de cette communauté monastique.

L'enquête sur le terrain reste aujourd'hui inachevée : une importante campagne de fouille est encore nécessaire pour terminer l'exploration de l'église conventuelle et des extérieurs, et pour révéler les aménagements de la fontaine; parallèlement, une prospection autour du Mont Beuvray doit apporter des éléments de comparaison sur lcs tcchniques ct les matériaux de construction et sur l'organisation spatiale des aménagements.

Cette recherche, intégrée aux travaux des autres équipes du Centre archéologique européen, livre des éléments riches et originaux tant sur l'histoire de l'ordre franciscain que sur celle du Mont Beuvray; la conservation et la restauration des vestiges, sans gêner l'étude des structures antiques sous-jacentes, devraient en assurer la lisibilité culturelle.

P. B., W. B., C. C., K. G., J. L., B. St-J.-V., C. S.

\section{L'ORGANISATION SPATIALE DE L'OPPIDUM}

Les vestiges remontant à La Tène $\mathrm{D}$ et à l'époque augustéenne atteignent une ampleur incomparable avec les faibles traces des périodes précédentes. Ils se caractérisent par la mise en place d'une voirie, la maîtrise de la circulation des eaux, la construction de fortifications, la délimitation d'espaces publics ou religieux qui structurent un habitat étendu sur une surface considérable.

\section{LES FORTIFICATIONS}

La fortification du Mont Beuvray, bien que masquée aujourd'hui sous les arbres et sous ses propres éboulis, reste un des monuments les plus spectaculaires que nous aient légués les populations de l'Âge du Fer (fig. 8). La hauteur du rempart, précédé d'un fossé et d'une contrescarpe qui dessinent aujourd'hui à son pied une large terrasse, le classe déjà parmi les fortifications les mieux conservées du monde celtique. Mais c'est surtout la continuité du tracé, ininterrompu sur $5 \mathrm{~km}$, qui force l'attention. Bulliot (1899, I, p. 1-95) avait déjà reconnu cette volonté de dresser une limite artificielle entre l'espace urbain et la campagne, soulignée encore par des portes monumentales. Déchelette avait fait les comparaisons qui s'imposaient avec Manching (Allemagne) et Stradonice (République tchèque). L'archéologie confirme ici le témoignage des textes qui attribuent à Bibracte le rôle de capitale d'une des plus puissantes tribus de la Gaule.

La reconnaissance d'une seconde fortification, englobant celle de Bulliot, est l'un des apports les plus neufs des campagnes de fouilles et de prospection récentes (fig. 4). L'acquisition des pentes de la montagne par l'État et leur nettoyage consécutif ont permis de découvrir ce nouveau rempart qui se confondait jusque-là avec les multiples chemins, antiques ou modernes, se croisant et se recoupant jusqu'à la base du massif. F. Schubert a parcouru en tous sens ce territoire et effectué des relevés minutieux pour chaque ondulation du terrain. Il a pu avancer de solides hypothèses qui seront à confirmer par des fouilles dans les années à venir. Ce rempart " externe » entoure une surface de près de 200 ha, équivalente à celle qu'occupe la ville d'Autun; toutes les observations sur les microreliefs semblent indiquer qu'il est antérieur au rempart " interne ». Cette séquence chronologique, si elle est confirmée par des sondages, nous amènera à re considérer l'évolution de l'oppidum, et surtout l'écart entre le programme initial et l'étendue effective de l'agglomération.

Les prospections géophysiques sur les clous du murus gallicus, conduites par A. Hesse et K. Aitchison, ont permis jusqu'à présent de repérer cinq fiches de fer sur le rempart externe. C'est bien sûr un indice insuffisant pour en tirer des conclusions : il faudra attendre le résultat des fouilles entamées par l'université de Vienne 


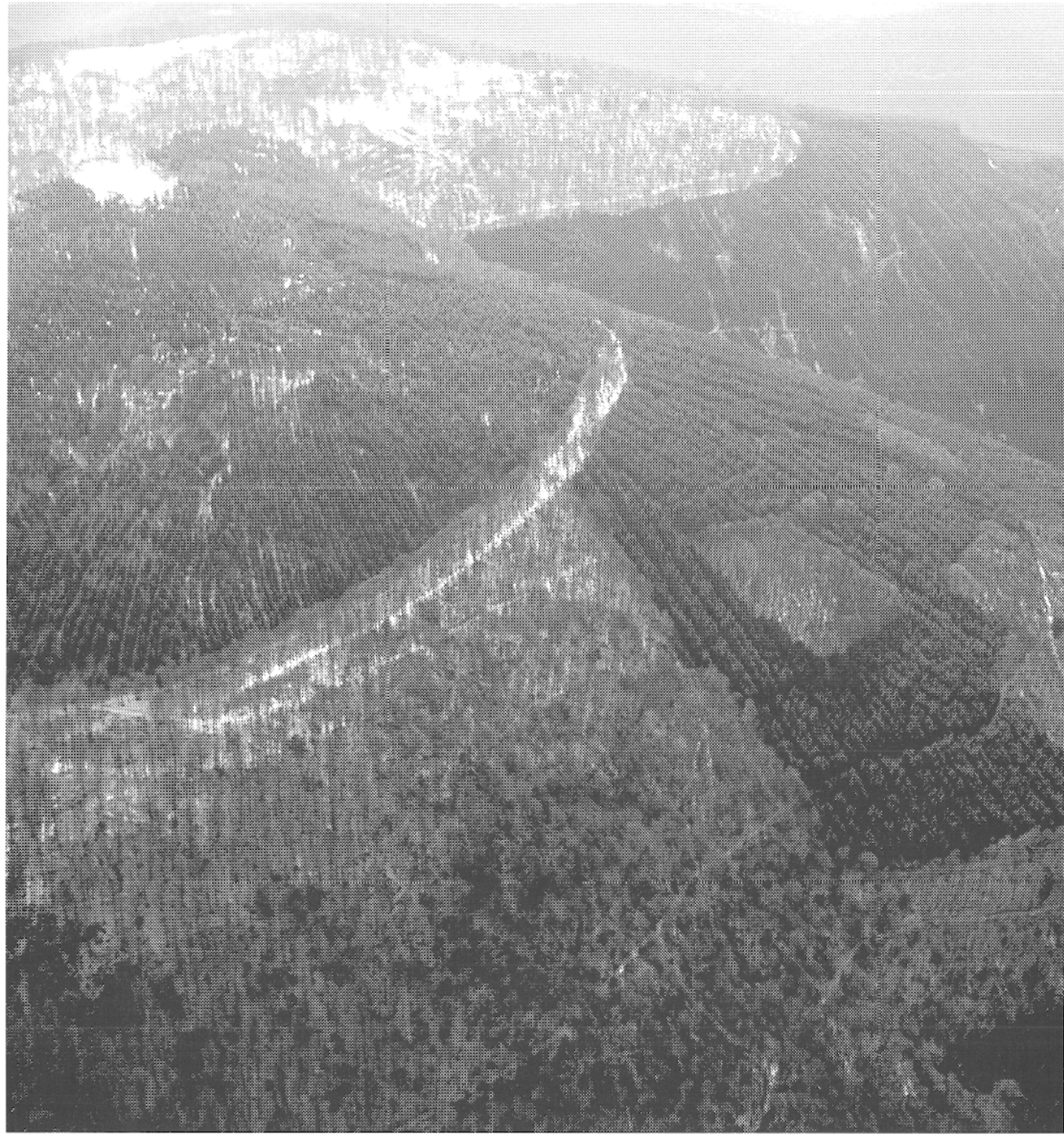

Fig. 8 - Vue aérienne du rempart supérieur sur le flanc occidental du Mont Beuvray. On distingue aussi au premier plan un tronçon. de la fortification extérieure (photo R. Goguey).
(Autriche) en 1995 pour connaître la datation et la nature de ce rempart.

La découverte de clous, grâce à cette méthode, dans ce que nous pensions jusque-là être l'axe des Grandes Portes, révèle que la fortification interne elle-même a connu plusieurs phases. Des reprises dans son tracé, ou des irrégularités manifestes, sont visibles en plusieurs endroits. Les fiches, dont la présence a été détectée à proximité des Grandes Portes ou de la Porte du Rebout, sont toujours placées dans la pente du talus couronné de pierres qui marque le tracé actuel de la fortification : le murus gallicus est en réalité partiellement enfoui sous un talus de terre, et c'est ce dernier que nous voyons lorsque nous suivons le tracé du rempart.
C'est la fouille de la Porte du Rebout qui a permis de mettre en évidence la succession de plusieurs phases de fortification pour cette entrée du type classique à ailes rentrantes (Zangentor), mais de proportions monumentales. Le talus, couronné d'une accumulation de pierres disposées sans ordre, est large au sommet de quelques mètres, alors que son emprise au sol dépasse nettement les $10 \mathrm{~m}$ (fig. 9). Il est d'autant plus facile à repérer dans la porte qu'il suit l'aile rentrante nord. À sa base, le long de cette aile, la masse des terres est retenue par une construction en poutres de bois horizontales, dont nous avons retrouvé l'empreinte dans les sédiments et l'ancrage dans le sous-sol. Nous ne pouvons pas affirmer que cet aménagement est strictement contemporain du 

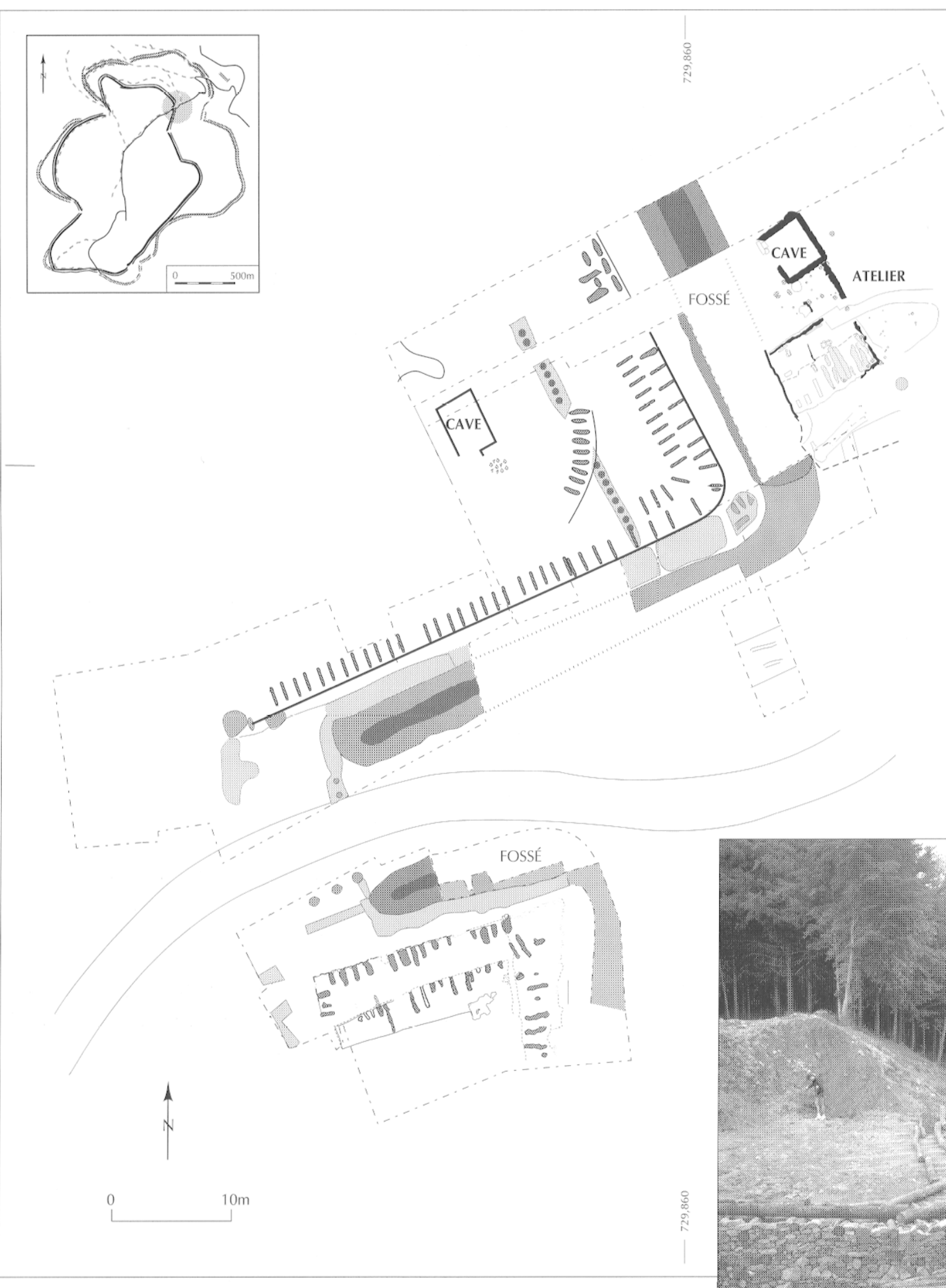

Fig. 9 - Plan de la fouille de la Porte du Rebout (état fin 1991) et vue (vers le nord-ouest) du bastion septentrional en cours de reconstitution.

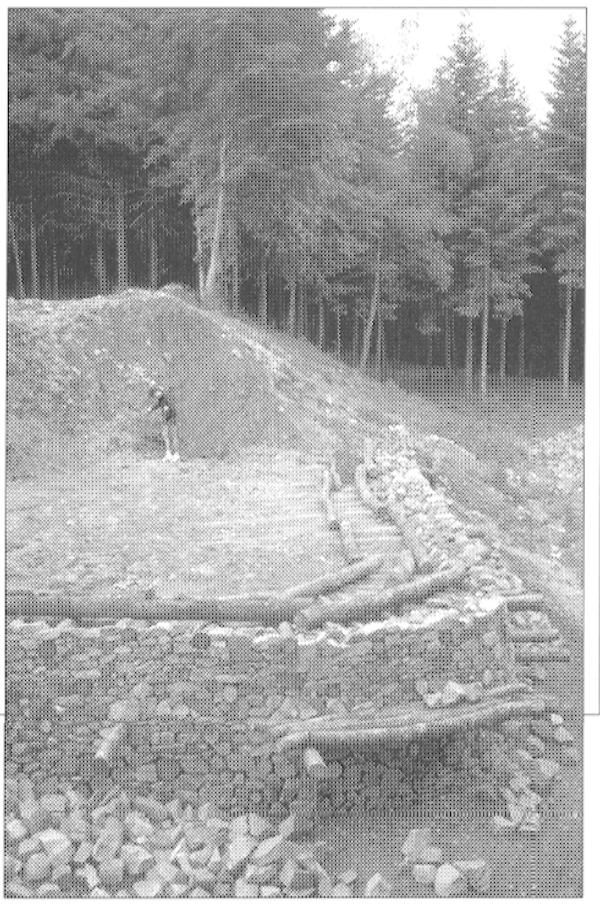


couronnement de pierres, les fouilles de nos prédécesseurs ayant interrompu les stratigraphies, mais cela reste très probable. Ce talus, scellé par des habitats de l'époque augustéenne, est à dater entre la conquête et le début de l'ère chrétienne. Ici, comme sur de nombreux oppida du nord de la France, un talus massif recouvre le rempart à poutrage interne et à paroi verticale externe.

Le murus gallicus, exploré à la Porte du Rebout sur plus de $1000 \mathrm{~m}^{2}$, présente une charpente interne classique, constituée de poutres horizontales entrecroisées (fig. 10). La taille de la fouille, exceptionnelle pour ce genre de construction, a permis maintes observations qu'il n'est pas possible de résumer ici ( 250 poutres horizontales, longitudinales et transversales, ont été relevées). Un premier état de ce murus gallicus, comportant également un parement en pierres et des poutres clouées, mais de diamètre plus fin que celles du murus gallicus principal, a pu être observé, suivant un tracé oblique par rapport aux parements est et sud de l'aile nord. Dans l'aile sud, une structure analogue a été mise au jour; de plus, deux phases successives peuvent être distinguées dans le murus gallicus principal. Même s'il n'est pas possible de généraliser à toute la fortification les observations faites sur cette porte, point particulièrement sensible, la rapide succession des reconstructions dans un laps de temps inférieur à un siècle ouvre de nouvelles problématiques.

Le mobilier recueilli dans le murus gallicus est relativement pauvre et les ensembles sont souvent pollués par le contact avec les couches de surface ou par les tranchées pratiquées avant nous par Bulliot. Heureusement, une couche d'occupation plus ancienne permet de caler sa chronologie. Des lambeaux de foyers et de sols d'habitat livrent en effet un mobilier typique de La Tène D1, et une datation dendrochronologique situe l'abandon de cette couche après 90 avant $\mathrm{J}$.-C. Le talus qui recouvre le murus gallicus livre du mobilier antérieur à 10 avant J.-C.

Sous les sols d'habitat de La Tène Dl ont été observés plusieurs calages de puissants poteaux. Ils déterminent une palissade parallèle au murus gallicus plus récent, dont la datation précise demeure indéterminée.

La fouille a enfin permis de reconstituer les principales phases d'évolution de la porte. Sa largeur exceptionnelle de $19 \mathrm{~m}$, déjà signalée par Bulliot, est confirmée par nos observations. Il s'agit bien, et de loin, de la plus large porte fortifiée du monde celtique. Elle est comparable à la Porte d'Arroux à Autun, ou encore aux

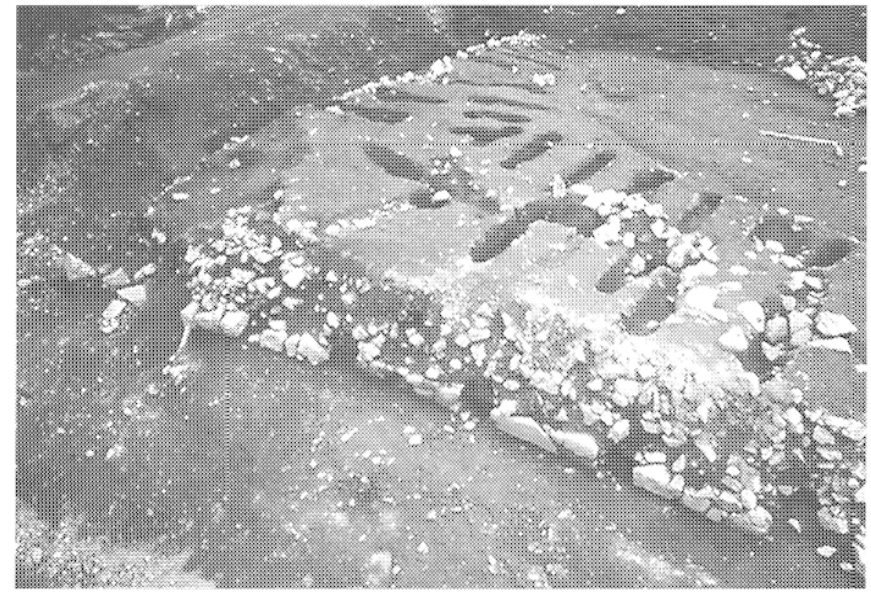

Fig. 10 - La Porte du Reboul : Le bastion seplenlrivnal en cours de dégagement, vu vers l'ouest.

portes que C.-N. Ledoux avait construites autour de Paris. L'érosion naturelle et les destructions opérées par les routes successives à travers la porte antique ont rendu très difficile la détection du sol du passage et des traces d'une éventuelle superstructure. Nous pouvons néanmoins affirmer aujourd'hui qu'il n'y a jamais eu ici un grand portail avec un étage ou un passage supérieur sur poteaux plantés comme on en connaît dans cercains autres grands oppida. Il faudrait en effet que cette construction n'ait pas été ancrée dans le sol, ce qui serait surprenant eu égard aux techniques architecturales de l'époque. La fouille a révélé des traces peu cohérentes de palissades et d'encadrement de portes tenus par des clous au fond du couloir formé par les deux ailes de la porte rentrante. Dans une phase de réfection, l'entrée est réduite en largeur : deux petits fossés courent en effet à la base du rempart, devant le poutrage qui garnit la base du talus. Il est possible que la porte ait été bloquée, mais les vestiges sont trop fugaces pour confirmer et dater avec précision cet événement. Dans la phase la plus tardive de l'occupation de l'oppidum, des constructions à caractère domestique ou artisanal viennent enfin s'installer dans l'emprise même du rempart, tandis que se resserrent les constructions de même type en avant de la porte, de part et d'autre du chemin d'accès.

En un siècle à peine, la Porte du Rebout a vécu une histoire agitée. D'abord monumentale, et sans doute indéfendable, elle constitue un large couloir entre deux spectaculaires parements de pierre et de bois. Au moment où, peut-être, l'on construit déjà à Autun la 
Porte d'Arroux, elle est réduite en largeur et sa parure de pierres a pratiquement disparu. Conserve-t-elle du moins une valeur militaire ? Il faudrait savoir si elle est alors en première ligne, ou si elle est encore protégée par le rempart externe.

Les remparts de Bibracte constituent à l'évidence un élément fondamental de l'oppidum: on les a reconstruits à de nombreuses reprises, on a modifié aussi bien leur tracé que leur technique de construction, on a lutté contre des conditions naturelles difficiles, mais il était apparemment indispensable de souligner les limites de la ville. Le même souci se manifeste à Augustodunum qui est doté, dès sa fondation, d'une enceinte maçonnée flanquée de 62 tours et percée de 4 portes monumentales.

O. B., I. B. M. R., F. S.

(Olivier Buchsenschutz, Ian Ralston, Franz Schubert)

\section{ÉVALUATION DE LA DENSITÉ DE L’OCCUPATION}

À l'époque de Bulliot, le Mont Beuvray est en pâtures et en bois. Les recherches ont été menées en fonction de ce paysage, se limitant généralement aux espaces dégagés. Cela explique que des zones comme le Porrey, à l'est du site, ou la région des Grandes Portes n'aient pas été explorées. Cela n'implique pas, en revanche, que tous les espaces dégagés aient été fouillés ou prospectés. Les fouilles ont été implantées en premier lieu sur des sites livrant des indices clairs d'occupation, tels que talus, terrasses ou arases de murs, puis se sont développées et étendues en fonction de l'abondance des découvertes ou le long des chemins contemporains.

Aujourd'hui, le Mont Beuvray est presque entièrement couvert de forêts, à tel point que des clairières ont dû être ouvertes pour permettre les nouvelles recherches (fig. 11). La prospection systématique des secteurs non encore étudiés est rendue difficile par la densité du couvert végétal, mais les premiers résultats confirment que Bulliot et Déchelette n'ont fouillé que partiellement le site.

Les sources principales qui permettent d'aborder l'étude de l'organisation spatiale de l'oppidum sont donc les documents du XIX ${ }^{\mathrm{e}} \mathrm{s}$. Bulliot et Déchelette ont en effet privilégié les dégagements superficiels et étendus, au détriment de l'approche stratigraphique. La réflexion est néanmoins subordonnée à deux facteurs importants qui touchent à la qualité des informations.

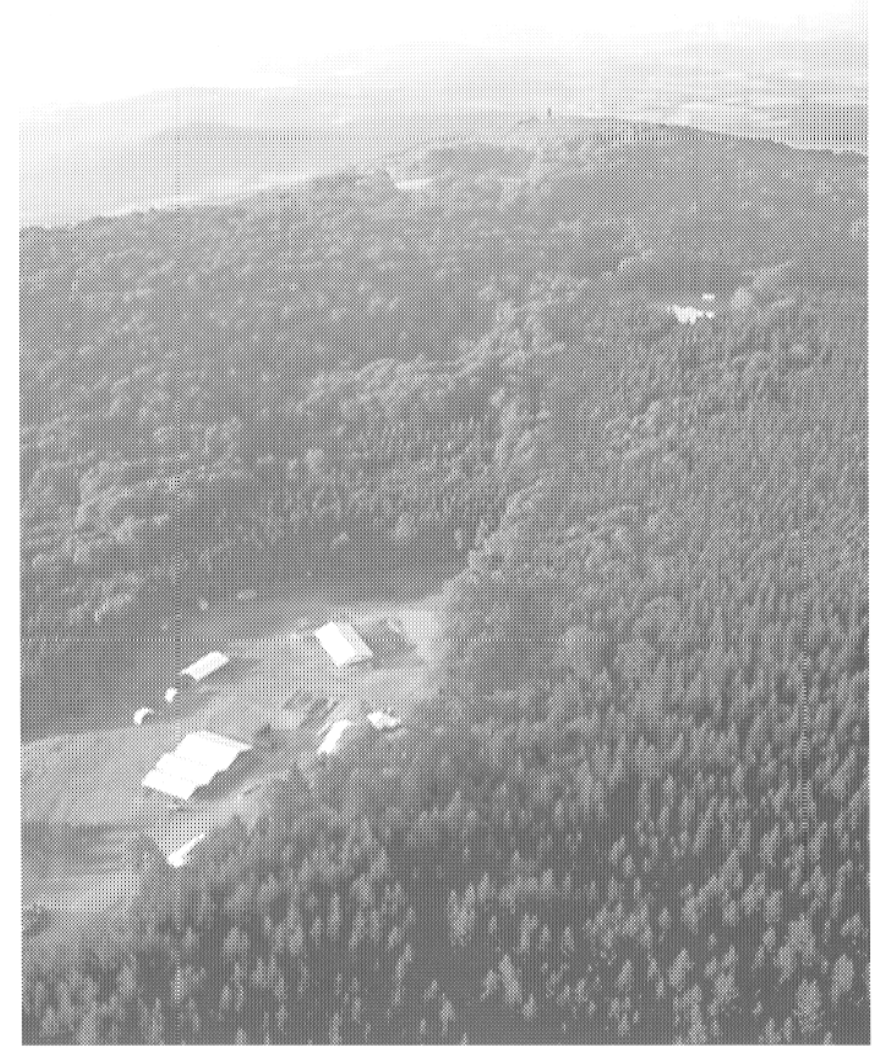

Fig. 11 - Vue aérienne du Mont Beuvray vers le sud, montrant les principaux secteurs de fouille : au premier plan, la Pâture du Couvent; au deuxième plan à droite, le Parc aux Chevaux; au dernier plan, la Chaume.

Le premier facteur est topographique. Le repérage des constructions est imprécis et nuit au discours sur l'organisation urbaine. Une erreur de près de $45^{\circ}$ sur l'orientation de la maison $\mathrm{n}^{\circ} 33 \mathrm{du}$ Champlain a ainsi pu être enregistrée (RF, 1994, p. 36), et la distance séparant deux bâtiments du Parc aux Chevaux, donnée en 1895 comme étant de $100 \mathrm{~m}$, se trouve en fait valoir $150 \mathrm{~m}$, vérification faite sur le terrain en 1995 . Le second facteur, tout aussi délicat, est celui de la chronologie. Les structures dégagées au XIX ${ }^{e}$ s. sont rarement datées, ce qui pose le double problème de leur datation absolue et de leur synchronie. L'essentiel du plan général montre par conséquent un assemblage de bâtiments livrés dans leur état d'abandon respectif. Les constructions étudiées ces dernières années ont été abandonnés entre le milieu du règne d'Auguste et le règne de Tibère, mais il paraît prématuré de projeter ces résultats à l'ensemble du site. 
L'enjeu scientifique des recherches sur la topographie de l'oppidum a suscité la mise en place d'un programme spécifique en 1994, destiné à contrôler la précision des relevés des fouilles anciennes, grâce à un réexamen méticuleux des archives, à des relevés microtopographiques et à des sondages. Ce programme a pour l'instant été appliqué surtout aux secteurs du Parc aux Chevaux et du Champlain. Associé aux résultats des fouilles systématiques menées parallèlement sur l'habitat, au Parc aux Chevaux (domus PC 1) et à la Pâture du Couvent, il permet de mieux évaluer les dispositifs architecturaux développés sur le site, et ainsi d'en appréhender la lecture, sans forcément inscrire tous les sites dans un objectif de fouilles au sens strict.

La reprise des fouilles a permis de constater deux faits importants. D'une part, les plans des bâtiments connus par les fouilles du XIX $\mathrm{e}$. ne sont pas forcément complets (par exemple l'îlot des Grandes Forges ; Szabó, in : RF, $1995,1)$. D'autre part, on constate une succession d'occupations structurées entre la fin du II ${ }^{\mathrm{e}}$ s. avant J.-C. et l'abandon du site - ainsi à la Pâture du Couvent (Vitali, in: RF, 1995, 2) ou à la domus PC 1 (Paunier, in: RF, 1995, 2) -, qui semble se retrouver dans les aménagements successifs de la voirie. Par ailleurs, les travaux de prospection sur des zones vierges nous autorisent à compléter, en partie, les données du XIX ${ }^{e}$ s. Ainsi, une microtopographie du secteur nord-est du Parc aux Chevaux a mis en évidence sept terrasses non fouillées au $\mathrm{XIX}^{\mathrm{e}} \mathrm{s}$., dont certaines portent de nettes traces de constructions maçonnées (fig. 12).

En l'état des connaissances, on peut définir deux grands types d'occupation pour l'espace intra muros: les zones à forte occupation et celles qui semblent laissées délibérément inoccupées. Par occupation, nous entendons les espaces d'activité (habitat, artisanat, culte, etc.) matérialisés par des structures. Des zones inoccupées existent au sud de l'oppidum, dont certaines sont interprétées comme des carrières. Des sondages au nordouest de la Terrasse (Gruel, in: RF, 1995, 1, fig. 2) et sur une vaste terrasse à l'est des Grandes Portes (Buchsenschutz, Ralston, in : RF, 1992, p. 127-130) ont mis en évidence des fronts d'extraction de matériaux, sans indice fort d'occupation antérieure ou postérieure. Le résultat de ces sondages, négatifs sur le plan des découvertes archéologiques, montre clairement que cette zone de l'oppidum, exposée au sud et propice à l'installation d'habitations, a été en réalité très peu habitée.
On peut donc avancer dès maintenant qu'il restait des espaces inoccupés dans l'oppidum.

À l'inverse, les régions du Champlain et la Côme Chaudron, en bordure du chemin montant de la Porte du Rebout, sont caractérisées par un grand nombre de petits bâtiments en terre et bois ou en pierre, d'organisation très simple. À la Pâture du Couvent, les fouilles modernes étendues autour du bassin monumental permettent d'entrevoir une trame urbaine serrée, organisée autour d'un grand axe nord-sud (fig. 13). Une voie secondaire perpendiculaire sépare ainsi l'îlot des Grandes Caves, au nord, du vaste ensemble des Grandes Forges, qui s'étend sur près de $6400 \mathrm{~m}^{2}$.

La partie orientale du Parc aux Chevaux, telle que la montre le plan de Bulliot corrigé (Meylan, in: RF, 1995, 3, p. 6-9), offre l'image d'un groupement assez lâche de grandes maisons alignées de part et d'autre d'une voie large de 8 à $12 \mathrm{~m}$, séparées les unes des autres par des enclos ou des espaces vierges (non fouillés). Le tissu semble ici moins dense que sur les secteurs précédents, mais les résultats de prospections récentes modifient cette apparence. En effet, des terrasses rapprochées et bien marquées dans la pente descendant vers la Pâture du Couvent suggèrent la présence de plusieurs bâtiments inexplorés. L'une d'entre elles, voisine de PC 8 au nord et explorée en tranchées, a partiellement livré le plan d'une domus à péristyle et a donné une cohérence à deux structures éparses ( $\mathrm{n}^{\text {os }} 35$ et 36$)$ en les intégrant au plan de cette maison dite des Pierriers (fig. 12).

Les recherches récentes permettent d'aborder plus précisément certaines questions inévitables sur l'urbanisme à Bibracte, à savoir la présence d'un ou de plusieurs plans directeurs et la chronologie respective de leur mise en place.

À la période augustéenne, il semble clair que l'occupation s'organise autour d'axes forts. La question est alors de savoir si cette trame s'appuie sur un canevas protohistorique ou si elle est créée dans la dynamique de la romanisation.

Les fouilles entre les maisons PC 1 et PC 2 du Parc aux Chevaux ont montré qu'une voirie construite est en place au moins dès l'état 3 de PC 1 , c'est-à-dire le milieu du I Ir s. avant J.-C., avec des réfections ou des reconstructions jusqu'à l'époque tibérienne (Dufay, in: RF, 1995, 3, p. 26), (fig. 15).

À la Pâture du Couvent, l'étude de la voie et des abords du bassin a également permis de distinguer diffé- 


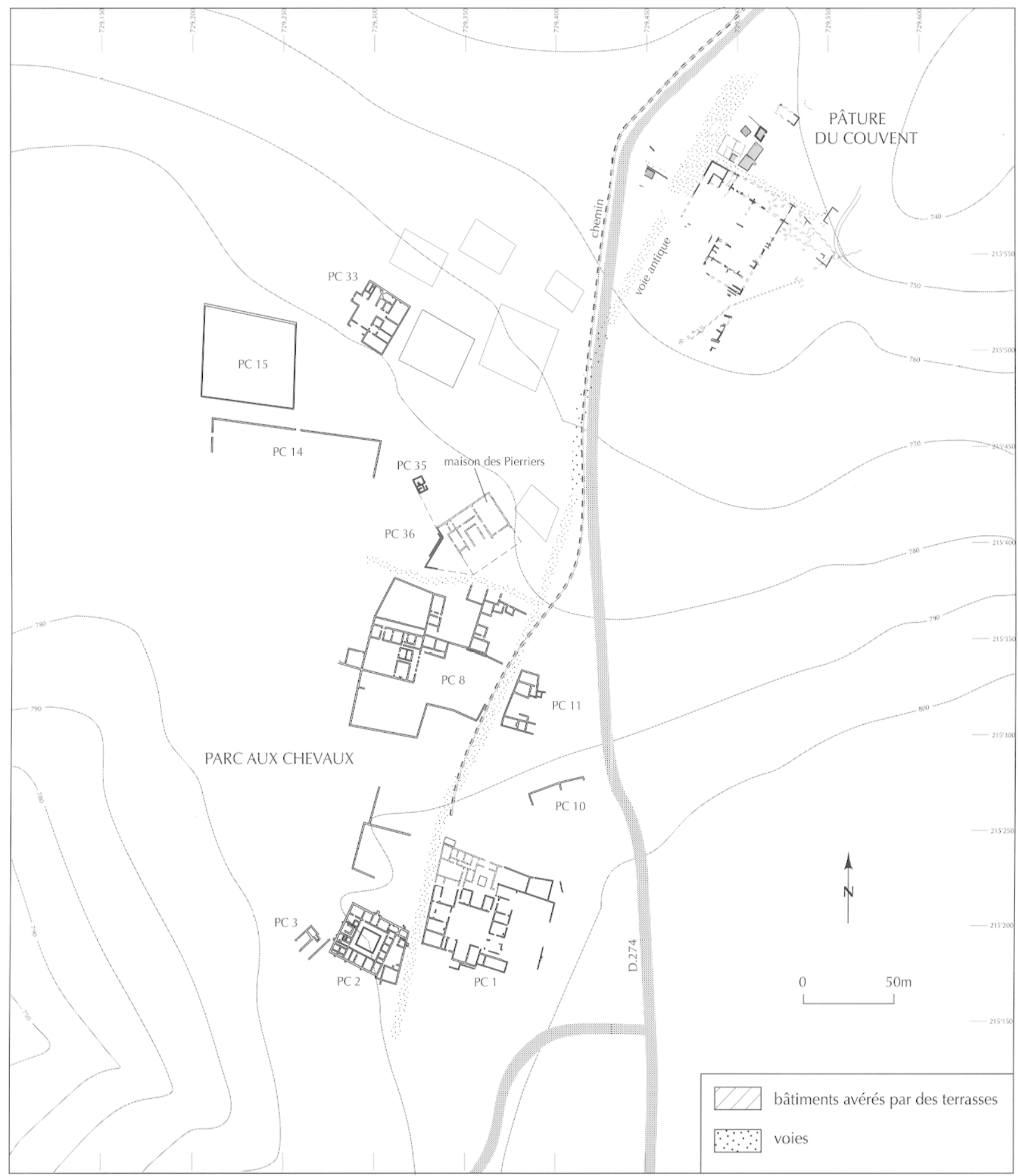

Fig. 12 - Plan synthétique des vestiges antiques du Parc aux Chevaux et de la Pâture du Couvent. 


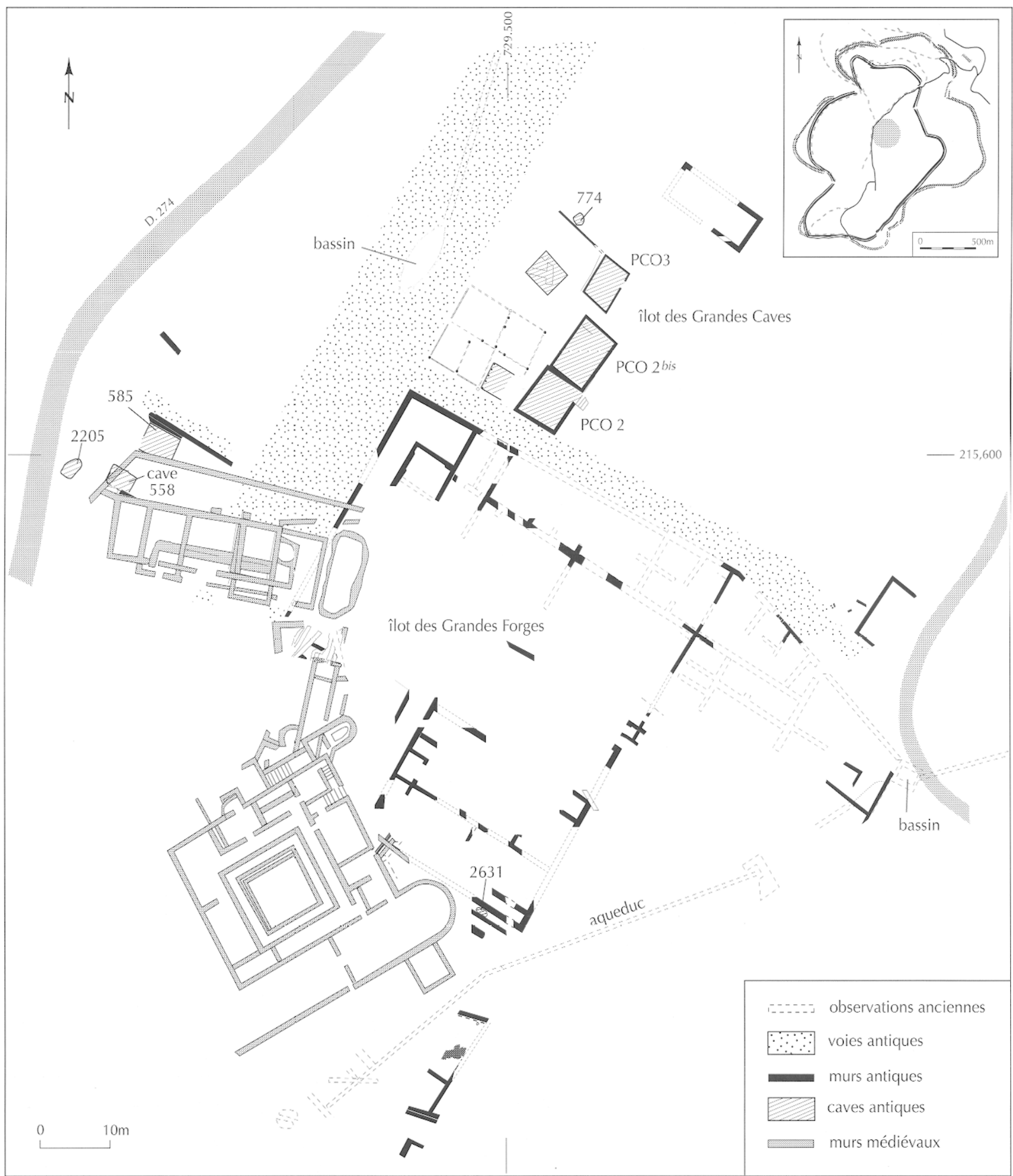

Fig. 13 - Plan synthétique des vestiges archéologiques de la Pâture du Couvent. 
rentes phases qui s'échelonnent sur la durée du $\mathrm{I}^{\mathrm{er}} \mathrm{s}$. avant J.-C. (fig. 16 et p. 27).

Les deux principaux sites de recherche mentionnés ci-dessus ont livré une épaisse stratigraphie allant de la fin du II's. avant J.-C. au début du $\mathrm{I}^{\mathrm{er}}$ s. après J.-C. En y ajoutant les observations faites par les archéologues du XIX's., sur PC 2 ou PC 33 par exemple (Meylan, in : RF, 1995, 3, p. 14-15 ; Bulliot, 1899), qui ont des états antérieurs de même orientation, on constate que les axes de construction n'ont quasiment pas varié au cours du $\mathrm{I}^{\mathrm{er}} \mathrm{s}$. avant J.-C. Des réfections ou des adaptations à la voirie ont eu lieu, dans la partie orientale de PC 2 ou sud de PC 36 par exemple, mais les secteurs fouillés, dans leur ensemble, donnent l'impression d'une permanence des grands axes (voir tout particulièrement le cas de la domus PC 1, fig. 20). Il n'en reste pas moins que la trame urbaine demeure irrégulière, pour se plier aux contraintes de la topographie. En témoigne par exemple l'orientation anormale de certaines maisons sur la pente nord du même secteur, comme PC 33 ou la maison des Pierriers.

On est donc amené à formuler la conclusion que, dans l'état actuel des connaissances, l'assimilation de techniques romaines de construction ne s'est pas accompagnée de remise en cause fondamentale de la trame de la voirie et des quartiers, qui semble fixée avant le milieu du I ${ }^{e r}$ s. avant J.-C.

Enfin, une brève étude métrologique des structures maçonnées du Parc aux Chevaux montre l'existence de modules récurrents, ce qui prolonge les observations du même ordre effectuées à propos du bassin monumental de la Pâture du Couvent (Almagro-Gorbea, GranAymerich, 1991, p. 156-157) : trois bâtiments s'inscrivent en effet dans un carré d'environ $30 \mathrm{~m}$ de côté, c'est-à-dire 100 pieds antiques, et quatre autres, dont le plan n'a pas été dégagé complètement, ont une longueur ou une largeur semblable.

F. M.

(François Meylan)

\section{LA GESTION DES EAUX ET LA VOIRIE}

\section{LES EAUX}

Si des raisons politiques, économiques et géographiques permettent d'expliquer le choix fait par les Éduens d'installer une ville sur le Mont Beuvray, le nombre des sources et la relative fiabilité de celles-ci sont aussi déterminants. Malgré le nombre important de ces points d'eau, une dizaine au total, les recherches sur le bilan hydrique de l'oppidum montrent que la disponibilité en eau devait pourtant être fortement déficitaire en cas de sécheresse prolongée (Plassiard, 1990 ; Boyer, in : RF, 1993, p. 241-245). C'est pourquoi la gestion des eaux, la régulation des voies internes et de leur trame, qui sont des questions clés sur tout site urbain, se révèlent d'un intérêt particulier pour l'oppidum de Bibracte.

Le Morvan est une des réserves hydrologiques de France, mais sa forte pluviosité et son sous-sol cristallin accentuent les phénomènes d'émergence et de ruissellement sur les pentes. Le site du Mont Beuvray bénéficie ainsi d'un nombre important de sources, situées à l'intérieur ou près du rempart interne comme les

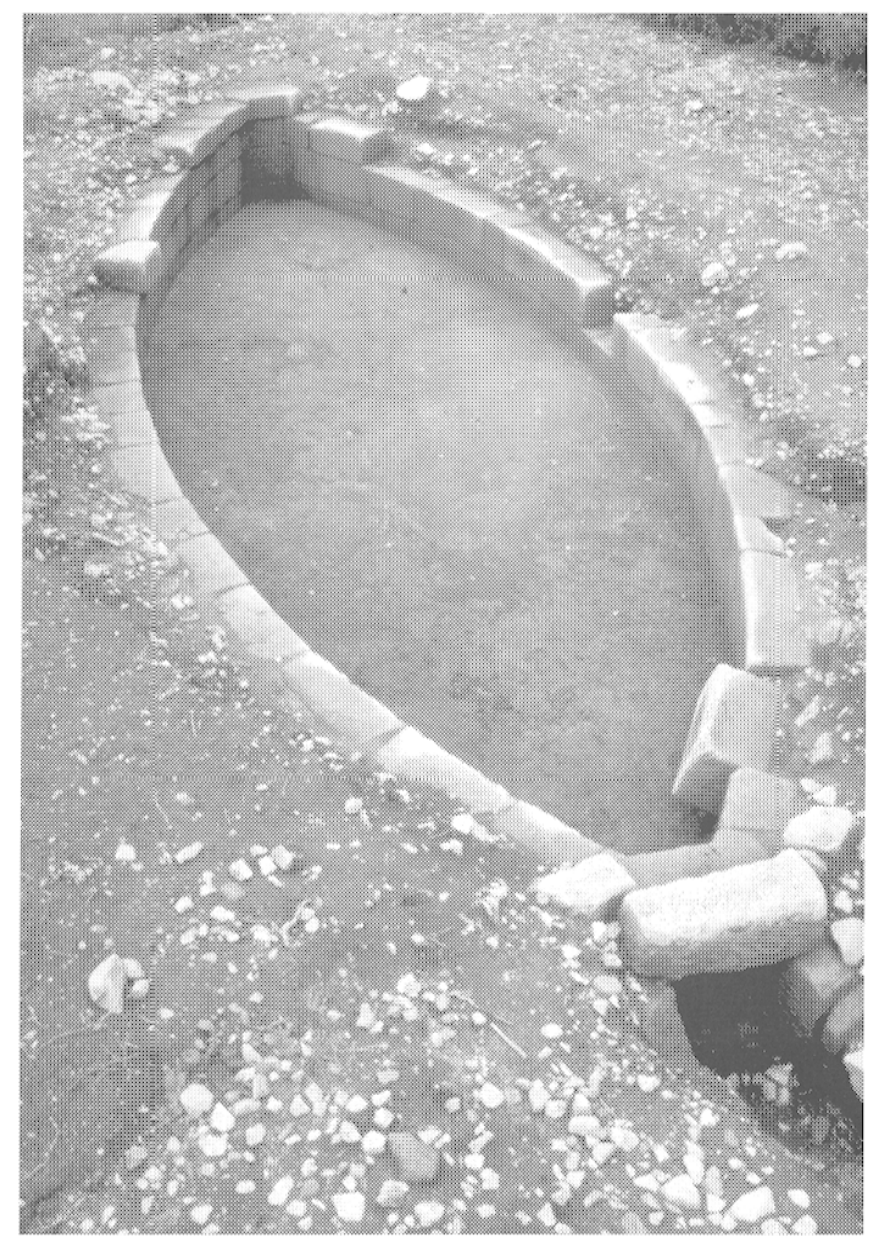

Fig. 14 - Le bassin monumental de la I'âture du Couvent, vu vers le sud-ouest. 
fontaines Grenouillat, Saint-Martin,. Saint-Pierre, du Petit Bois, de la Chaintre du Mitan, du Loup Bourrou, de l'Écluse, des Larmes, du Chevreuil, ou encore la pièce d'eau du Couvent (ressortant plus en aval sous le nom de ruisseau de la Côme Chaudron). Les fouilles ont livré les vestiges de différentes sortes de canalisations (en bois, en céramique, en pierre) et une ouvre de plus grande envergure, l'aqueduc maçonné et voûté issu de la pièce d'eau identifiée au sud du couvent (fig. 13).

De nombreux bassins ont été repérés : à la Fontaine Saint-Pierre, au quartier de la Côme Chaudron, dans l'enceinte de plusieurs domus du Parc aux Chevaux, contre la façade de la domus PC 1, dans l'axe de grande voie de la Pâture du Couvent. On note que plusicurs d'entre eux, situés à la résurgence d'une source ou sur une voie publique, sont destinés à l'usage collectif. Cet usage est souligné par une construction souvent soignée, en pierre de taille, voire parfois monumentale, comme pour le bassin naviforme de la Pâture du Couvent (Almagro-Gorbea, Gran-Aymerich, 1991).

Le bassin monumental de la Pâture du Couvent, placé sur la voie principale, à l'intersection avec la rue des Caves, fournit le meilleur exemple d'un monument des eaux (fig. 14). L'érosion du revêtement de la voie, en amont du bassin, n'a pas permis de localiser son alimentation; sa vidange, par une canalisation en bois, a en revanche été suivic sur un tronçon de près de $30 \mathrm{~m}$, sous l'empierrement de la voie principale.

\section{La voie principale, de la Porte du Rebout À la Pâture du Couvent}

Du fait des fortes dénivellations du site, l'aménagement de la voirie revêt une particulière importance, tant pour les communications que pour la gestion des eaux de ruissellement. Les fouilles récentes, depuis 1987, ont apporté des renseignements précis sur le mode de construction de plusieurs axes : à la Porte du Rebout, sur la Pâture du Couvent (rue principale et ruelle transversale, fig. 13), dans le Parc aux Chevaux et en contrebas de la Terrasse, avec des largeurs de près de $14 \mathrm{~m}$ pour la voie principale, et de 4 à $5 \mathrm{~m}$ pour les voies secondaires comme la ruelle de la Pâture du Couvent. Ces voies sont aménagées avec la technique du " macadam à l'eau », qui superpose les sables et graviers naturels, des couches de fragments d'amphores et des revêtements caillouteux irréguliers damés, dans un limon argileux jaune, le substrat local.

La voie qui, de la Porte du Rebout, remonte le long du talweg de la Côme Chaudron puis débouche sur la Pâture du Couvent est sans doute un des principaux cheminements qui traversent l'oppidum. Son prolongement vers le sud est incertain. Deux tracés sont discernables, sans que l'on puisse savoir si l'un prévalait sur l'autre. Le premier traverse le Parc aux Chevaux (où il a été fouillé récemment entre les façades des maisons PC 1 et PC 2 ; fig. 15), puis se prolonge vraisemblablement jusqu'aux Grandes Portes, via la Fontaine Saint-Pierre. Le second remonte vers la Chaume, où il a été observé au XIX ${ }^{e} s$.

Quelles que soient les incertitudes subsistantes, la construction de la grande voie repérée sur la Pâture du Couvent fut sans doute un moment fondamental dans l'élaboration de la structure urbaine à Bibracte, ce qui explique que l'on ait minutieusement cherché à reconstituer son histoire. Cet axe présente en effet plusieurs niveaux de circulation superposés (fig. 16 et 17).

L'état initial ("voie 0 ») correspond à une première chape de graviers et de tessons d'amphores, épaisse de $10 \mathrm{~cm}$ et installée dans un léger surcreusement du substrat. Comme la voie du deuxième état («voie $1 \mathrm{~A} »)$, elle est d'une largeur totale d'environ $9 \mathrm{~m}$ et est tronquée à l'ouest par la tranchée de fondation du mur de façade (502) de l'îlot dit des Grandes Forges. La voie lA était longée à l'ouest par un fossé peu profond $(30$ à $35 \mathrm{~cm}$ ), comblé lors du troisième rechapage («voie $1 \mathrm{~B} »)$ qui s'est traduit par un élargissement de 3,2 m dans cette direction. Il est logique de penser que cette modification est contemporaine de la construction du bassin monumental qui occupe l'axe de la nouvelle voie élargie. Un dernier exhaussement ( voie 2 ») a enfin eu lieu après le renforcement du mur de façade nord-ouest de l'îlot des Grandes Forges.

Les sondages effectués depuis 1990 du côté ouest de la voie ont révélé plusieurs niveaux d'habitation pour lesquels une chronologie relative fine a pu être établie. Une structure interprétée comme un petit portique de $7 \mathrm{~m}$ x 1,5 m lié à la façade d'un bâtiment (voir aussi infra, p. 39) est parallèle à la voie $1 B$ et séparée d'elle par un logement de sablière. Le sol de ce portique est composé de petits tessons d'amphores bien damés qui reposent sur une couche de fragments plus importants. En dessous, on a constaté l'existence d'unc prćparation particulière constituée de tessons d'amphores et de cailloutis. 


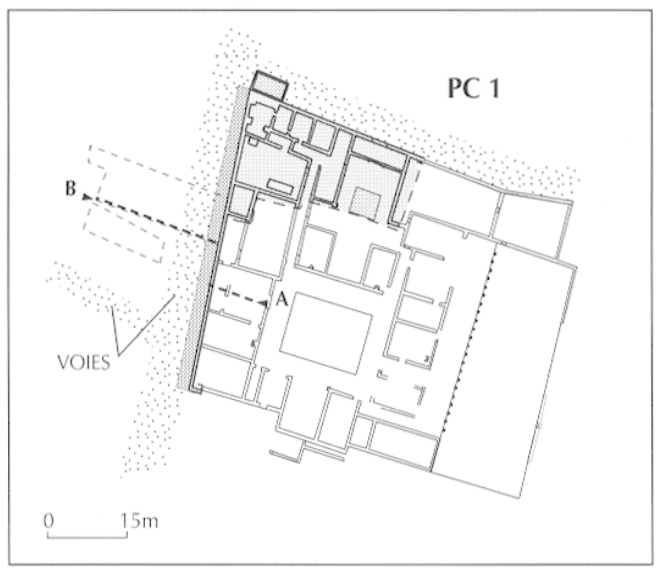

sud-est

sud-ouest

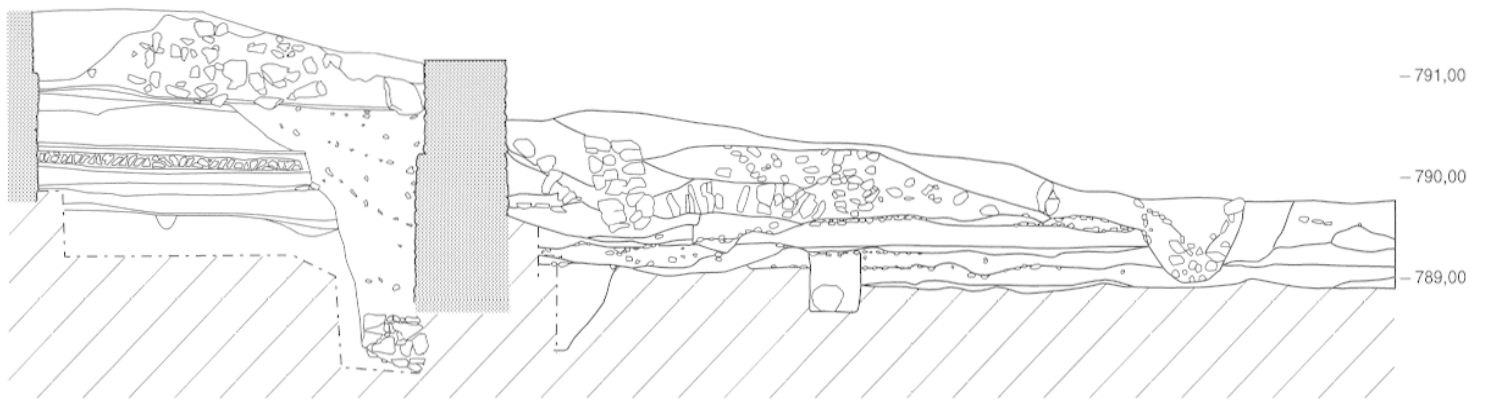

A

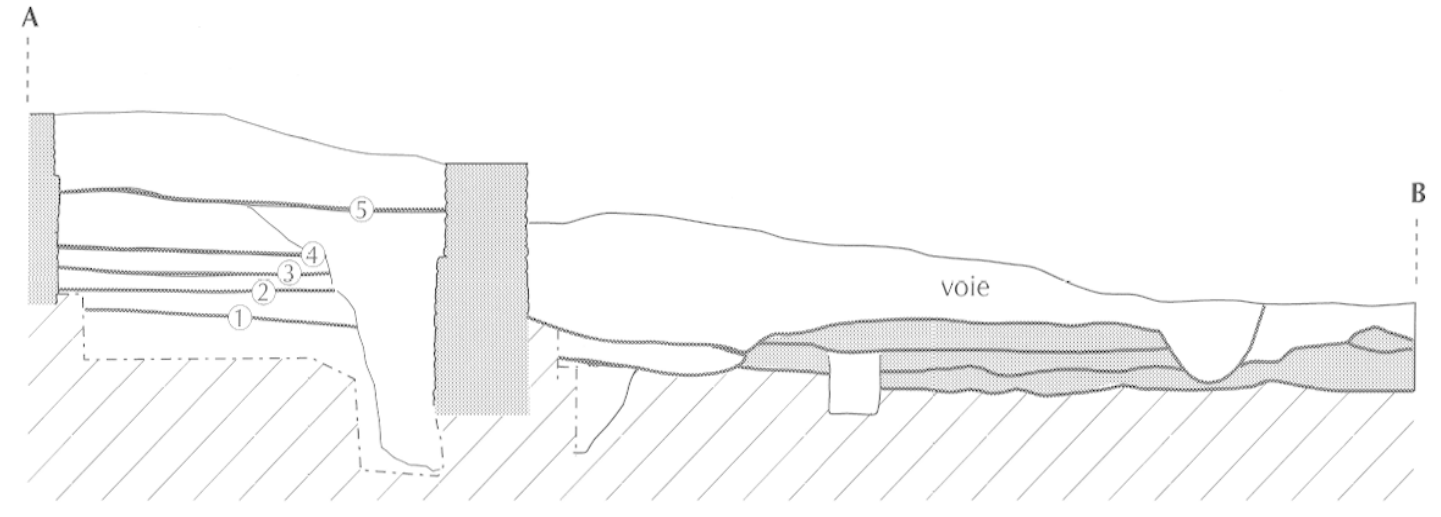

Fig. 15 - Coupe stratigraphique partielle de la domus PC l el de la voie qui la borde à l'ouest. 


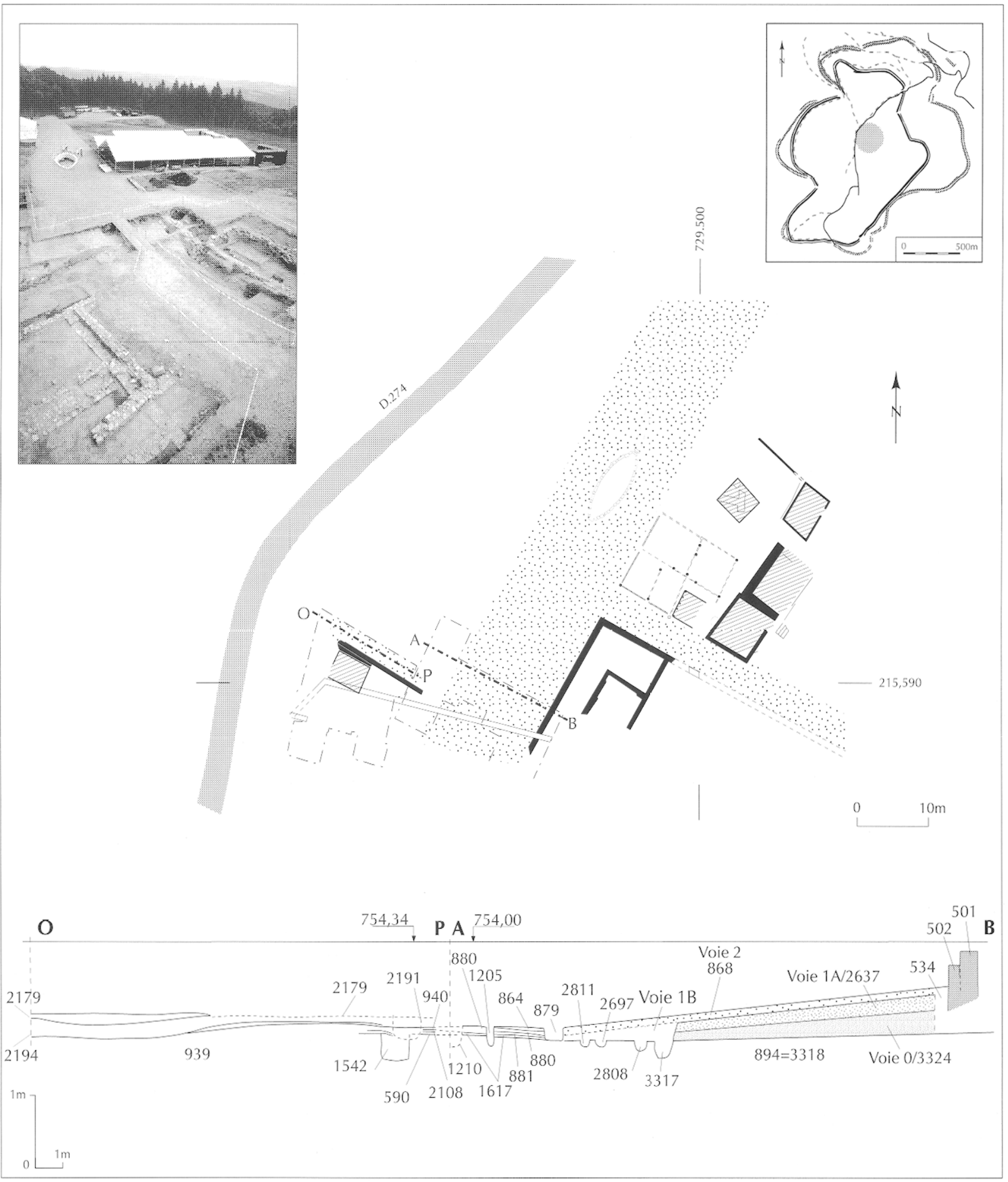

Fig. 16 - Vue vers le nord et coupe transversale de la grande voie de la Pâlure du Couvent. 


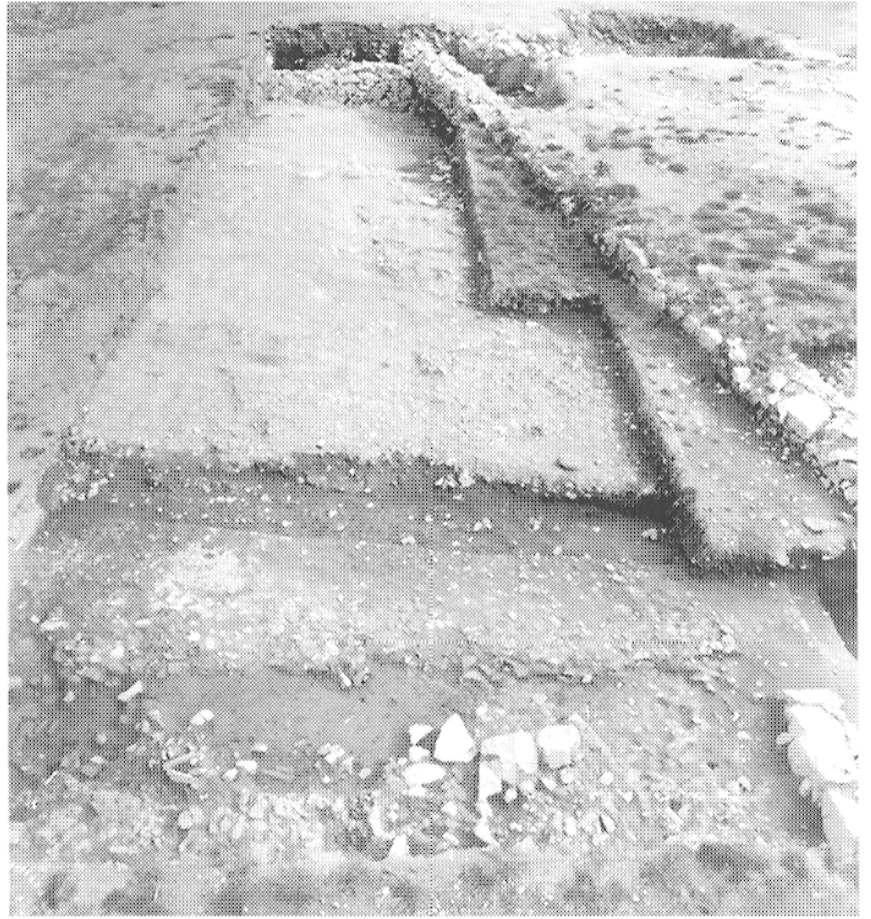

Fig. 17 - La grande voie de la Pâlure du Couvent dans son dernier état, vue vers le sud-est : au premier plan, le caniveau 879; au dernier plan, le mur 501 ; $a$ droite, le mur de clôture du couvent.

L'alignement des trous de poteau du côté ouest du portique confirme l'idée que cette construction est en harmonie avec la voie.

Divers éléments stratigraphiques permettent de préciser la chronologie de l'ensemble. Les plus anciennes structures sont des fosses et trous de poteau repérés sous la voie 0 , mais malheureusement arasés et dépourvus de mobilier. Sous le portique occidental et le sol de la même période, qui passe sous la voie $1 \mathrm{~B}$, se trouve un niveau d'argile jaune contenant des structures d'orientations différentes de celles de la voie, trous de poteau, fosses, foyer, etc. Le remplissage des fosses contenait beaucoup de scories, de charbons de bois et cendres, qui font penser à une activité métallurgique dans la zone, à l'ouest des voies plus récentes. Deux d'entre elles (PCO 1618 et 1660) avaient au fond un remplissage de céramiques, et, dans la partie supérieure, une couche constituée avant tout de tessons d'amphores soigneusement étalés. La datation qui en est proposée ( $c f$. annexe I, p. 100), à la fin du II ${ }^{\mathrm{e}} \mathrm{s}$. ou au début du $\mathrm{I}^{\mathrm{er}} \mathrm{s}$., fournit donc un terminus post quem pour l'installation de la voie $1 \mathrm{~B}$ et, par conséquent, la construction du bassin. En prenant en compte les repères chronologiques de la construction de l'îlot des Grandes Forges, la datation de la voie 2 peut quant à elle correspondre à l'époque augustéenne, ce que conforte l'examen du mobilier issu de son radier. Cette voie est donc liée à la phase d'urbanisme tardive de Bibracte, c'est-à-dire au dernier tiers du $\mathrm{I}^{\text {er }}$ s. avant J.-C., qui s'achève avec la désaffection du quartier et le comblement du bassin, daté du milieu du règne d'Auguste (Montesinos i Martínez, in : Almagro-Gorbea, GranAymerich, 1991, p. 292-294).

\section{La voirie dans le secteur de la Chaume ET DE LA TERRASSE}

Bulliot avait repéré sur une assez grande distance la voie quasiment nord-sud qui, issue de la Pâture du Couvent, remonte vers la Chaume où elle sépare le péribole du sanctuaire et la Terrasse (fig. 18), pour enfin dévaler vers une porte nettement discernable dans le rempart (B6). Une autre voie a été reconnue récemment, qui contourne la Terrasse par l'ouest pour aboutir à la même porte. Fouillée sur plus de $7 \mathrm{~m}$ de longueur en contrebas de la Terrasse, elle s'incline avec une pente régulière de $5 \mathrm{~cm}$ par mètre. Plus en aval, son tracé est encore nettement discernable dans la topographie moderne.

Dans son état le plus ancien, cette voie est large de $4 \mathrm{~m}$; elle est constituée d'un cailloutis de rhyolite pris dans un limon argileux. En contrebas, s'ouvrait une vaste carrière de pierre; son abandon et son remblaiement partiel ont permis l'élargissement de la rue, qui passe alors à $8 \mathrm{~m}$. Probablement par crainte d'un effondrement, cette nouvelle voie fut soutenue à l'ouest par un renfort en bois. Ces poteaux de soutènement, de section carrée, sont fichés dans le sol, calés par de grosses pierres et solidement ancrés à leur partie supérieure par des poutres transversales, espacées de $2 \mathrm{~m}$ en moyenne et scellées dans le revêtement de la voie. On peut placer la date de construction de cette nouvelle voie vers le milieu du Ier s. avant J.-C. à partir de fragments de céramique grise à pâte kaolinique et d'un fragment de céramique à paroi fine à décor de guillochis. Un tesson de sigillée italique (assiette du service 1 de Haltern) montre qu'elle a fonctionné jusqu'à l'époque augustéenne.

F. B., A. D.-A., J. G.-A., K. G., F. S., M. S.

(François Boyer, Almudena Domínguez-Arranz, Jean

Gran-Aymerich, Katherine Gruel, Franz Schubert, Miklós Szabó) 


\section{LIEUX PUBLICS, LIEUX CULTUELS}

L'identification d'une organisation de type urbain exige la recherche des lieux destinés à des pratiques collectives, qu'elles soient religieuses, politiques ou économiques. Plusieurs zones susceptibles d'avoir rempli ces fonctions ont donc fait l'objet de fouilles.

\section{LA TERRASSE}

La Terrasse occupe un des sommets du Mont Beuvray. C'est une esplanade d'environ 1 ha $(110 \mathrm{~m} \times 92 \mathrm{~m})$, limitée par un talus doublé d'un fossé (fig. 18). Elle domine au sud la vallée de l'Arroux (Buchsenschutz, 1991). Bulliot l'avait identifiée avec un camp romain mais nos connaissances actuelles ne permettent pas de conserver cette hypothèse. Ce type d'enclos quadrangulaire de 1 ha, délimité par une levée de terre (de $50 \mathrm{~cm}$ à $2 \mathrm{~m}$ de hauteur), mais ne renfermant aucun vestige ou presque, est fréquemment décrit dans le monde celtique sous le terme de Viereckschanze et identifié comme un enclos supposé cultuel. Son existence est attestée en Bohême, en Allemagne du Sud et dans le Bassin parisien (Buchsenschutz, 1991).

La levée, plus massive aux angles, est constituée par la terre enlevée du fossé, profond d'environ 1,20 m, qui la borde. Les fouilles de X. Garenne sur le flanc nord avaient identifié une porte. La reprise de la fouille en ce point en 1987 a montré qu'il s'agissait d'une construction romaine placée dans le fossé et en bord de voie. Les fouilles n'ont en fait mis en évidence aucune interruption du fossé et ceci conformément au schéma habituel des Viereckschanzen. Sur le flanc sud, le talus était renforcé par des bois sur une longueur d'au moins $60 \mathrm{~m}$. Ceux-ci apparaissent comme les éléments d'un rempart de $2 \mathrm{~m}$ de haut constitué d'un parement de branches disposées horizontalement et maintenues par des poteaux de $20 \mathrm{~cm}$ de diamètre, en arrière duquel un talus d'argile constituait l'essentiel de la fortification. Ces bois ont brûlé et se sont consumés lentement. Les prospections menées à l'extérieur de l'enceinte, sur ses flancs ouest et sud, ont mis en évidence un renforcement de cette défense principale par des palissades concentriques à poteaux jointifs (trois à l'ouest, probablement deux au sud), écartées d'environ $4 \mathrm{~m}$. L'ensemble de ces aménagements ne présente pas un caractère véritablement défensif, il s'agit plutôt d'une limite isolant symboliquement cette esplanade des autres lieux de la cité.

L'espace réservé de la Terrasse, prospecté systématiquement par des méthodes géophysiques, ne recelait en revanche aucune trace d'aménagement et très peu de mobilier. Il est donc difficile de préciser la fonction de cet espace privilégié, situé en un des points les plus en vue du massif, que l'on a eu soin de préserver de toute construction. Les datations isotopiques et dendrochronologiques nous suggèrent une date de fondation remontant au III ${ }^{e}$ s. avant J.-C. (cf. note 4). Le talus, détruit lors d'un incendie, est scellé localement par une couche datée de La Tène $\mathrm{D} 2$. Il semble donc avoir perdu son rôle dans la dernière phase d'occupation de l'oppidum. Ceci nous conduit à émettre l'hypothèse que sa fonction devait être liée à la vie publique de la cité éduenne : assemblées, votes, élections, adjudications des charges, autant d'occasions citées par les textes antiques qui nécessitaient un lieu réservé et probablement consacré, car dans la société gauloise aucune activité collective importante ne devait se dérouler sans rituel.

\section{La Chaume}

Tout près de la Terrasse, au lieu-dit la Chaume, occupé encore aujourd'hui par la petite chapelle SaintMartin, des sanctuaires successifs ont sacralisé ce point du site jusqu'au début du XIX' s. (cf. supra, p. 13, fig. 5 et 18). Si quelques éléments celtiques ont bien été dégagés dans cette zone, qui ne permettent pas d'exclure qu'un sanctuaire plus ancien ait pu y exister ${ }^{6}$, le premier temple mis au jour est de type romano-celtique à cella carrée $(8,9 \mathrm{~m} \times 10,5 \mathrm{~m})$ et galerie périphérique. Sa date de fondation ne peut pas être précisée par le mobilier associé car les fouilles du XIX's., très importantes dans cettc zone, ont coupé toute liaison stratigraphique et enlevé les couches d'occupation. Ce premier édifice, orienté estouest, subit plusieurs réaménagements que Bulliot, peu sensible aux modes de liaison des murs, n'avait pas toujours perçu. La qualité des plans-masses vérifiée par les observations des fouilles permet une réinterprétation des plans anciens (Guillaumet, 1996, p. 134-144, plans 61-70). Le fanum fut rapidement enclos par un péribole,

6. La décision de conserver les murs dans l'éventualité d'une mise en valeur n'a pas permis de pousser la fouille plus avant. 


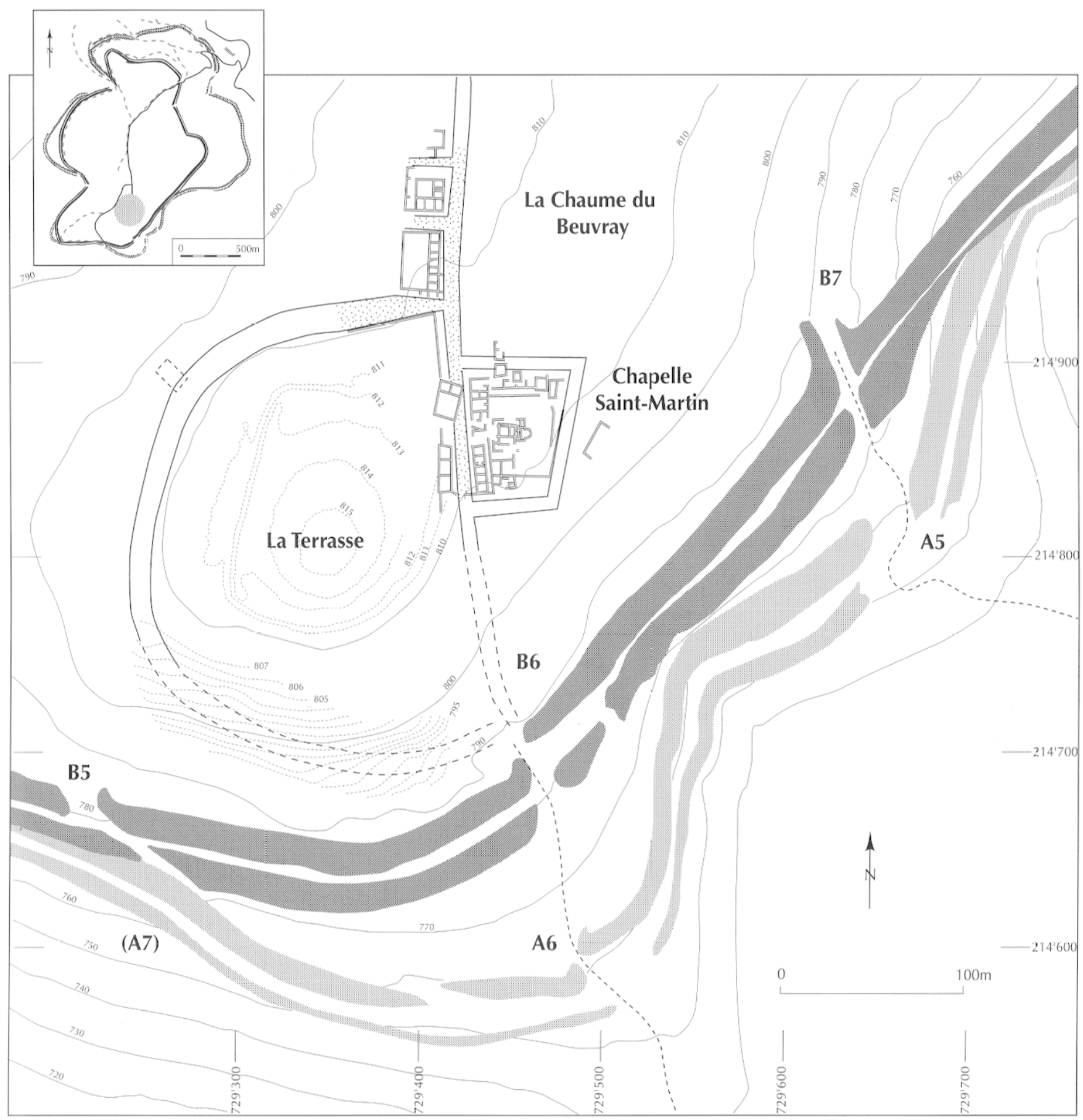

Fig. 18 - Le secteur de la Terrasse et de la Chaume avec la localisation des remparts, de la voirie et des bâtiments antiques. 


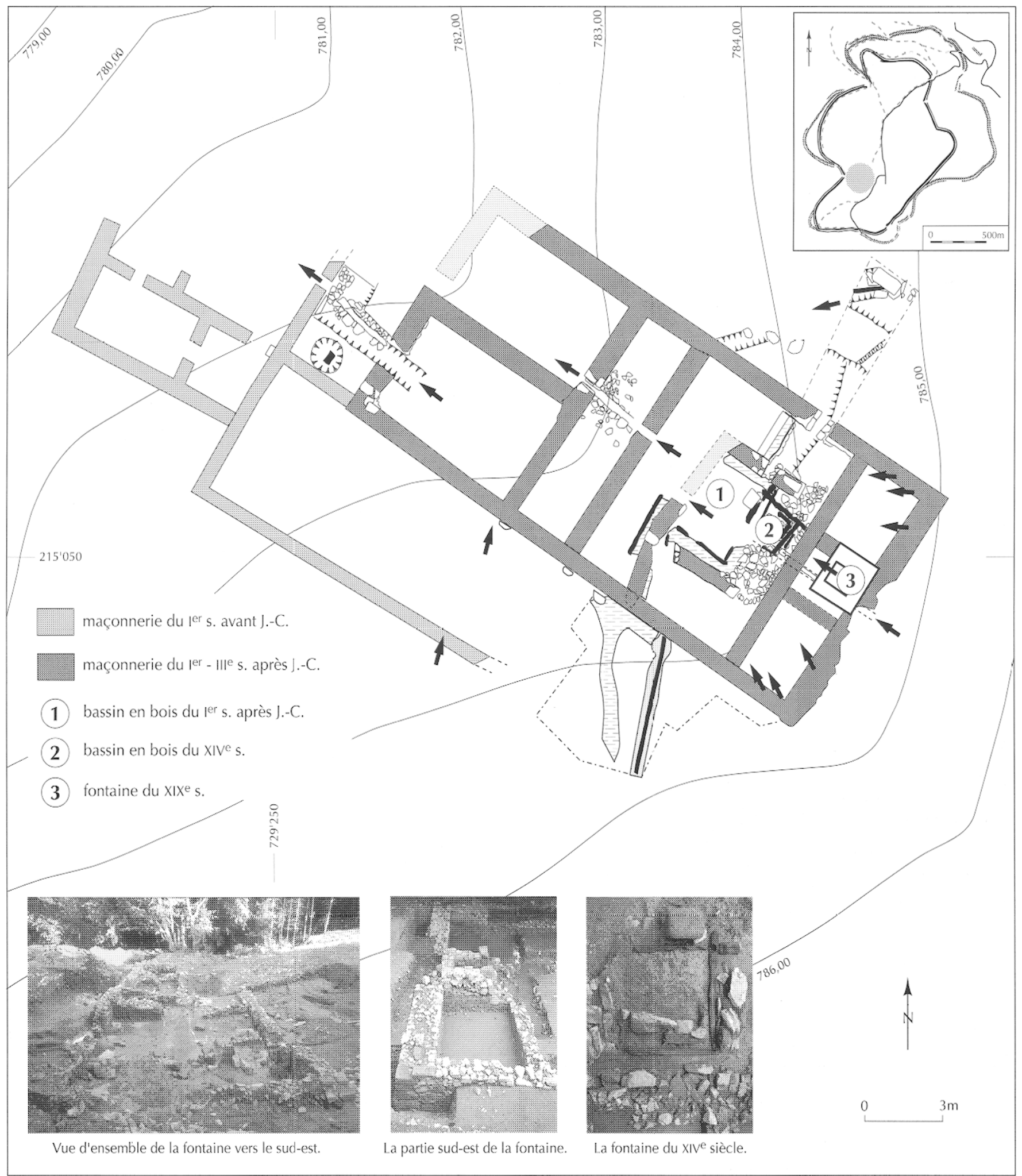

Fig. 19 - Plan général des fouilles de la Fontaine Saint-Pierre et vues de détail d'états anciens des bassins. 
auquel s'appuyait du côté ouest une rangée de boutiques ouvertes vers la rue. Il fut ensuite remplacé par une église à nef unique $(15,3 \mathrm{~m} \mathrm{x} \mathrm{8,8} \mathrm{m})$ puis par une chapelle rectangulaire $(8,65 \mathrm{~m} \mathrm{x} \mathrm{4,2} \mathrm{m})$, pour être finalement réduit à un simple oratoire ( $4 \mathrm{~m} \mathrm{x} \mathrm{4,2} \mathrm{m),} \mathrm{(Beck} \mathrm{et} \mathrm{al.,} \mathrm{1988).} \mathrm{On}$ a aussi proposé récemment l'identification d'un bâtiment exploré par Bulliot au nord du péribole à un mithraeum, dont il faudrait bien sûr placer la fondation à une date avancée de l'époque impériale (Goudineau, in: Goudineau, Peyre, 1993, p. 102-105). Les bâtiments reconnus dès le $\mathrm{XIX}^{\mathrm{e}} \mathrm{s}$. sur la Chaume s'organisent non pas comme un forum mais comme un vaste ensemble cultuel avec ses dépendances.

\section{LES SOURCES ET LES FONTAINES}

Toutes les sources du massif étaient probablement utilisées dans l'Antiquité, mais quelques-unes seulement devaient être aménagées. Seule à ce jour, la Fontaine Saint-Pierre a permis de démontrer l'existence de pratiques cultuelles ou superstitieuses liées à ces sites particuliers.

La source est aménagée sous la forme d'un vaste édifice rectangulaire maçonné de $20,5 \mathrm{~m} \times 10 \mathrm{~m}$, dont on ne peut restituer l'élévation (fig. 19). Les multiples objets découverts dans les niveaux d'aménagement et la couche de décantation permettent de proposer une utilisation de cet édifice durant une période qui couvre une grande partie de La Tène finale (Barral, Richard, in: Flouest et al., 1993). En l'état d'avancement de l'étude, il est toutefois impossible de garantir que les dépôts les plus anciens, datés de la fin du $\mathrm{II}^{\mathrm{e}} \mathrm{s}$. et du début du $\mathrm{I}^{\mathrm{er}} \mathrm{s}$. avant J.-C., soient en relation avec cet édifice ou qu'ils appartiennent à un état plus ancien d'utilisation dont les vestiges auraient presque entièrement disparu. La nature des objets fournit quelques précisions sur l'utilisation de ce monument : si les débris de récipients destinés au transport et au service des liquides (notamment des pieds de cruches métalliques) montrent que la source a logiquement été aménagée pour faciliter l'approvisionnement en eau des hommes (et peut-être des animaux), le nombre élevé des monnaies et leur état de conservation, souvent excellent, prouvent qu'elles n'ont pas toutes été perdues. Leur présence s'explique plutôt par des dépôts volontaires, fréquents en ce genre d'endroits et d'ailleurs encore pratiqués sur place au $\mathrm{XX}^{e} \mathbf{s}$. Quelques objets (en particulier une oreille en tôle de bronze) découverts dans les niveaux de fonctionnement de cet édifice ne peuvent également appartenir qu'à des ex voto.

Ces traditions perdureront, puisque les monnaies découvertes à l'intérieur de l'argile d'étanchéification de la fontaine carrée postérieure, datée entre 20 à 50 après J.-C., peuvent être associées à un rite de fondation de la construction.

K. G., H. R.

(Katherine Gruel, Hervé Richard)

\section{ÉVOLUTION DU BÂTI : TECHNIQUES LOCALES DE CONSTRUCTION ET INFLUENCES MÉDITERRANÉENNES}

Les résultats des fouilles récentes, tout particulièrement à la Pâture du Couvent (fig. 13) et au Parc aux Chevaux (fig. 20), apportent des données propices à l'étude de l'évolution de l'architecture et des techniques de construction mises en ouvre sur l'oppidum de Bibracte. En effet, bien que les publications qui les concernent mentionnent parfois des structures antérieures, les investigations du siècle dernier n'avaient permis qu'une lecture horizontale des types architecturaux du site, en rapport avec la phase ultime d'occupation.

Il s'agit ici d'une première approche qui devra être vérifiée et précisée, pour les dernières découvertes, par l'analyse approfondie des données de terrain. C'est pourquoi, dans l'état actuel des recherches, il est prématuré de proposer des plans comparés des quartiers aux différentes périodes d'occupation. Par ailleurs, les édifices les plus fréquemment rencontrés sont des caves, et les habitats correspondants n'ont pas toujours pu être mis en évidence en raison des nombreux recreusements et réfections qui se sont succédé dans les mĉmcs cndroits.

On peut cependant apprécier divers degrés d'évolution de l'architecture, de l'habitat traditionnel de petit module en terre et bois à la domus romanisée de plan très développé. Mais il convient de souligner dès à présent que ces deux types coexistent encore dans le dernier quart du $\mathrm{I}^{\mathrm{er}} \mathrm{s}$. avant J.-C. : la maison traditionnelle gauloise avec cave, qui peut recourir à des techniques de construction romaines, essentiellement l'usage de la maçonnerie, et la domus inspirée de modèles méditerranéens, tant au niveau des plans que des techniques mises en œuvre. 


\section{L'HABITAT GAULOIS}

La présence de caves et de fosscs cst attcstćc durant toute la période d'occupation de l'oppidum. Les deux plus anciennes ont été retrouvées au Parc aux Chevaux et à la Pâture du Couvent. Compte tenu de la datation du mobilier issu de leur comblement (cf. annexe I, p. 90 et 93), leur construction est vraisemblablement antérieure à la fin du II $\mathrm{s}$. avant J.-C.

$\mathrm{Au}$ Parc aux Chevaux, à l'emplacement de la grande domus PC 1, la première occupation (état 1) est constituée par une cave quadrangulaire (PC 130, étudiée dans l'annexe I, p. 93 et fig. 20) de $2 \mathrm{~m}$ x 2,6 m et profonde de $1,6 \mathrm{~m}$. Ses parois sont verticales et son fond plat. Une sablière borde son côté oriental et suggère l'existence d'un plancher ou d'une superstructure (Paunier, Luginbühl, à paraître). Une autre cave partiellement fouillée, des fosses que l'on peut supposer être des silos, profondes de 40 à $70 \mathrm{~cm}$, un sol aménagé ainsi qu'un foyer sont à mettre en relation avec elle. À l'ouest de cet ensemble se trouvent des traces d'habitat matérialisées par deux foyers constitués d'une chape d'argile sur radier de cailloutis, des fosses et quelques trous de poteau, implantés dans un sol de graviers damés, mais qui ne dessinent pas de plan cohérent.

Une autre fosse (PCO 2205), située à la Pâture du Couvent au sud-ouest du carrefour entre la grande voie et une voie secondaire (fig. 13 et 21a), possède un plan subrectangulaire de $2,5 \mathrm{~m} \times 2 \mathrm{~m}$ et est profonde de $0,7 \mathrm{~m}$ environ. On l'identifie à une cave par analogie avec la précédente, malgré l'absence de traces d'un coffrage en bois. Elle est en relation avec un habitat signalé par des trous de poteau. Les limites restreintes du sondage réalisé alentour ne permettent pas encore d'identifier la forme de l'édifice, construit entièrement en bois (Haffner, in: RF, 1992, p. 51-52). Le sol PCO 2192, distant d'environ $6 \mathrm{~m}$, présente un faciès de mobilier identique (étudié dans l'annexe I, p. 96) qui montre l'existence d'autres structures d'habitat contemporaines dans ce secteur, dont l'organisation reste pour le moment inconnue.

Dans le deuxième quart du $\mathrm{I}^{\text {er }} \mathrm{s}$. avant J.-C., on observe sur le site de PC 1 (état 2) la construction d'une grande cave de $8 \mathrm{~m} \times 10 \mathrm{~m}$, profonde de $2,5 \mathrm{~m}$ (PC 4696, fig. 20; mobilier étudié dans l'annexe I, p. 113), (Paunier, Luginbühl, à paraîtrc). Sa paroi nord cst oblique, alors que celle située à l'ouest est verticale. Un imposant trou de poteau à fond plat, de 70 à $80 \mathrm{~cm}$ de diamètre, est implanté dans l'angle sud-est qui comporte un sol irrćgulicr. L'accc̀s devait s'effectuer par le sud au moyen d'un plan incliné. Elle est bordée au nord par une palissade constituée de piquets de 5 à $10 \mathrm{~cm}$ de diamètre, espacés de $15 \mathrm{~cm}$ au maximum et implantés dans un fossé large de $40 \mathrm{~cm}$ (131). Une seconde palissade, ou un mur, se trouvait certainement du côté occidental, comme le suggère la présence de deux trous de poteau. Le sol à l'extérieur de la cave est constitué de limon damé. Ici encore, les aménagements ne permettent pas la détermination précise du plan de l'habitat : trous de poteau épars, trace de paroi repérée en coupe, fosse comblée de fragments d'amphores et deux foyers d'argile, dont l'un repose sur un radier de tessons d'amphores. L'ensemble de ces structures est circonscrit par une grande palissade de poteaux équarris de 40 à $60 \mathrm{~cm}$ de côté, implantés dans un fossé de $80 \mathrm{~cm}$ de profondeur. Cette palissade détermine un enclos dont le côté nord a une longueur de $28 \mathrm{~m}$. Son alignement sera repris par le mur de façade des états ultérieurs (3 et 4 ).

Il est probable que ces installations du Parc aux Chevaux et de la Pâture du Couvent sont contemporaines de l'atelier de forge de la Porte du Rebout, construit lui aussi entièrement en bois ( $c$. infra, p. 57 et fig. 36). Celui-ci a sans doute fonctionné en correspondance avec un espace domestique comprenant un silo, situé au nord, dont l'emplacement sera plus tard occupé par une cave.

Dans le secteur sud-ouest de la Pâture du Couvent, à l'ouest de la grande voie, ont été identifiées deux structures d'habitat entièrement en bois qui se succèdent en l'espace d'une génération, vers le milieu du I ${ }^{\mathrm{er}} \mathrm{s}$. Au premier état appartiennent une petite cave ou " garde-manger " parallélépipédique de $3,7 \mathrm{~m} \mathrm{x} \mathrm{2,7} \mathrm{m} \mathrm{pour} \mathrm{une} \mathrm{pro-}$ fondeur de $0,9 \mathrm{~m}$ (PCO 558; localisation sur la fig. 21a), un sol en terre battue d'argile jaune et de gravier, et deux rangées perpendiculaires de fosses rectangulaires, dont l'une située en façade (en façade : PCO 3250, 3249, 3246 ; 950 ; en retour : PCO 1567, 1560, 1542). La superficie restreinte de la fouille mais surtout les nombreuses réfections anciennes nous empêchent encore une fois d'avoir une idée exacte de la forme et de la surface originelles de l'édifice qui peut être actuellement identifié sur une largeur minimale de $12 \mathrm{~m}$, dans un axe est-ouest, ct sur une longueur d'environ $11 \mathrm{~m}$. On constate néanmoins l'implantation cohérente de la cave vis-à-vis de cet 


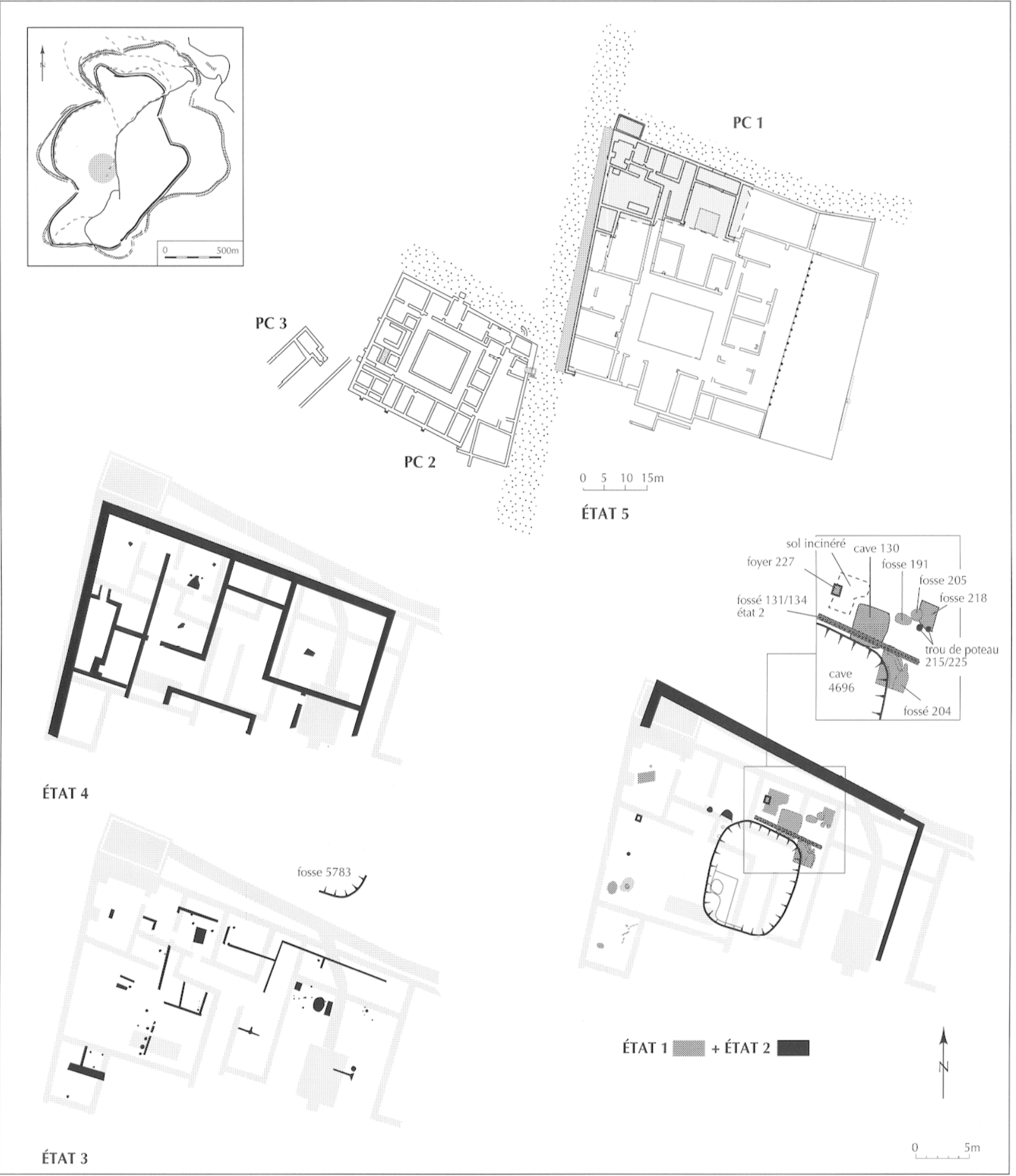

Fig. 20 - Les différents états de construction reconnus dans l'angle nord-ouest de la domus PC 1 (Parc aux Chevaux). 

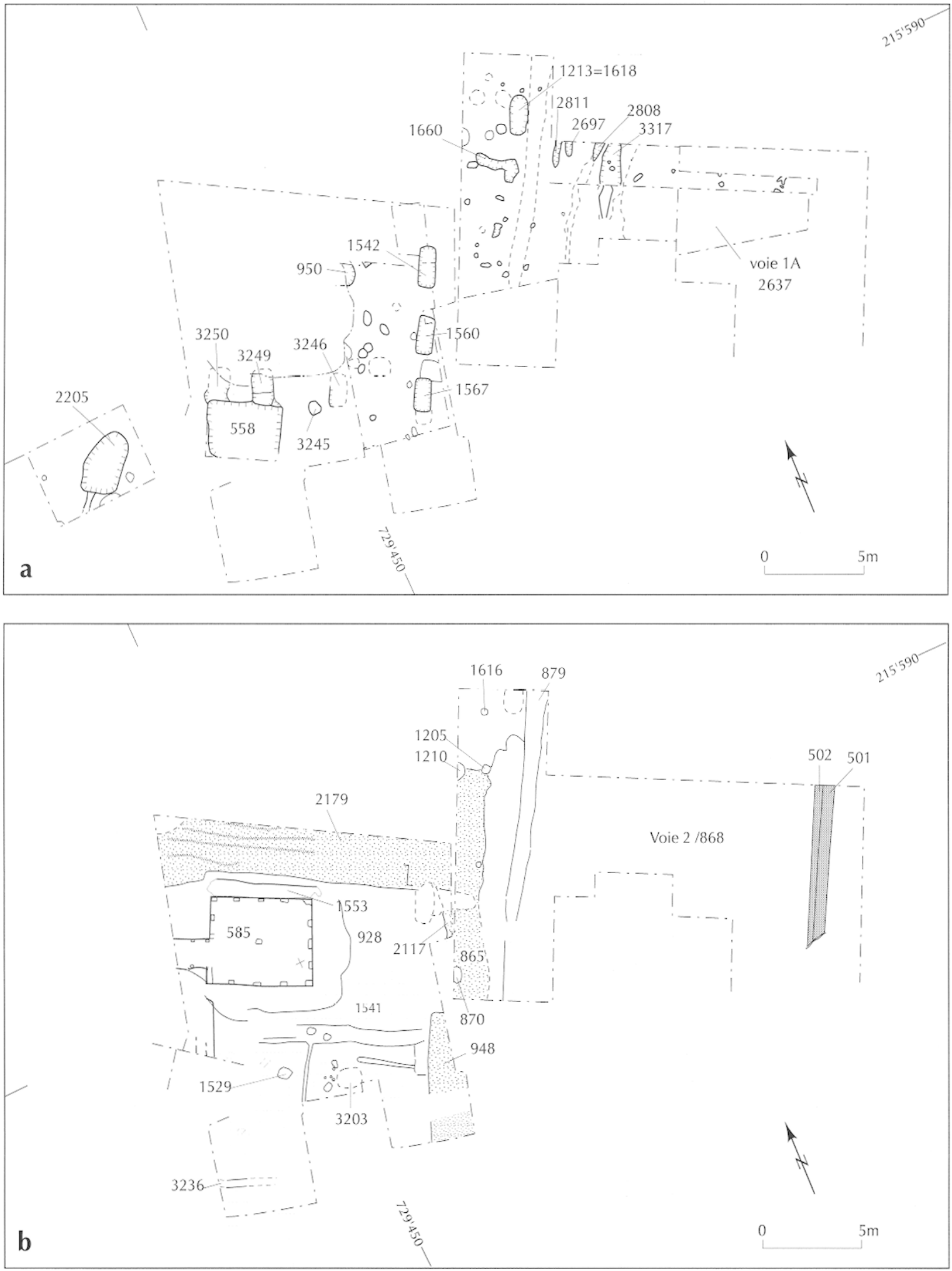

Fig. 21 - Plan des deux principaux états antiques de construction reconnus dans la parlie occidentale de la Pâture du Couvent : $a$, état ancien, $b$, état récent. 
ensemble. Dans un deuxième temps, la cave, qui demeure de même type, est déplacée légèrement vers le sud (PCO 553 ; mobilier étudié dans l'annexe I, p. 105), tout en demeurant probablement dans l'espace du même édifice.

Deux fosses (PCO 1660, $1213=1618$; fig. 21a), localisées entre 5 et $7 \mathrm{~m}$ au nord-est de cet ensemble, présentent des parallèles dans les modalités de leurs remplissages. Elles se trouvent dans l'espace vide compris entre la voie $1 \mathrm{~A}$ et le bâtiment de la cave PCO 558, et pourraient avoir appartenu à une structure du même type, mais la surface fouillée jusqu'à présent ne nous permet pas d'envisager un plan d'ensemble.

Au nord-est du carrefour de la grande voie et de la ruelle transversale se trouve le seul bâtiment dont nous connaissons l'extension totale (fig. 13) (Gran-Aymerich, Hernandez, in : RF, 1992, p. 37 ; RF, 1993, p. 27-28). Il est constitué d'un édifice pourvu d'une cave inscrite dans son angle sud-est. De plan presque carré, il présente une surface de $120 \mathrm{~m}^{2}$; les parois extérieures sont formées d'un alignement de poteaux ; une partition interne est également attestée par la présence de poteaux axiaux. La cave est large de 4,5 m x $4 \mathrm{~m}$ et profonde de 1,8 m. Ses parois sont renforcées par une armature de planches sur poteaux en bois, que l'on perçoit dans les couches incendiées de destruction. Le mobilier de son comblement est semblable à celui de la cave PCO 585 (fig. 21b et annexe I, p. 124) et date son abandon des années qui précèdent le changement d'ère.

Dans le même îlot, à environ $5 \mathrm{~m}$ plus au nord, on observe une seconde cave carrée en bois, de $3,85 \mathrm{~m}$ de côté et d'une profondeur de $2 \mathrm{~m}$ (RF, 1994, p. 20). Ses parois sont renforcées par des planchettes de $5 \mathrm{~cm}$ de largeur, calées par des poteaux dont on retrouve les traces aux angles et fixées par des clous distants de $85 \mathrm{~cm}$ environ. Sur le côté sud-est, près de l'angle, on retrouve les traces d'un escalier en bois hors œuvre. En l'état actuel des connaissances, il n'est pas possible de définir la physionomie de l'édifice correspondant (Bonenfant, in : RF, $1995,1)$.

\section{LES PREMIÈRES INFLUENCES MÉDITERRANÉENNES}

Les premiers emprunts faits aux techniques de construction méditerranéennes sont surtout perceptibles sur le site de la maison PC 1 , à l'état 3 , daté du troisième quart du I ${ }^{\text {er }}$ s. avant J.-C. (fig. 20). Plusieurs espaces d'ha- bitat présentent une même architecture : sablières basses reposant parfois sur un solin de pierres sèches, élévations en pans de bois et torchis, dont la couche de démolition est facilement identifiable, enduits muraux en mortier de chaux. La terre cuite architecturale fait également son apparition, sous la forme de couvertures de tegulae et d'imbrices. Les sols sont constitués soit de gravier damé qui semble marquer les espaces extérieurs, soit de limon graveleux jaune damé qui forme le sol des pièces, ou encore de tessons d'amphores posés à plat sur une fine couche de sable. Les foyers sont tous constitués d'une chape d'argile reposant sur un radier de tessons d'amphores. Une grande pièce rectangulaire de $80 \mathrm{~m}^{2}$, située à l'est, comporte un potéau central équarri de 20 cin $\mathrm{x}$ $40 \mathrm{~cm}$, ancré dans une fosse profonde de $90 \mathrm{~cm}$. La campagne de fouilles de 1995 a aussi mis au jour, au nord de cette construction, l'angle sud-est d'une cave ou d'un silo qui paraît appartenir à cet état. Ses parois sont renforcées par des poteaux de bois verticaux et le fond, situé à $2,2 \mathrm{~m}$ au-dessous du sol extérieur, est peut-être constitué d'un plancher de bois isolé par une couche de tessons d'amphores.

Le plan de ces maisons, lacunaire pour l'instant, semble néanmoins indiquer un type d'habitat traditionnel. Il se développe à l'est de la voie principale dont l'existence est certaine dès cette époque.

\section{LES ASPECTS DE LA ROMANISATION}

Dans le domaine de la construction, la romanisation, dont les premiers signes se manifestaient par l'emploi de tuiles et d'enduits à la chaux, s'affirme par le recours à la maçonnerie (fig. 25 et 26). Cette technique, qui ne fait son apparition qu'au début de la période augustéenne, ne se généralise pas immédiatement puisque des constructions en matériaux périssables coexistent avec celles en maçonnerie jusqu'à l'abandon de l'oppidum. C'est sans doute une des principales originalités du site que cette coexistence d'édifices parfaitement romains et d'autres fortement ancrés dans la tradition régionale.

Une cave entaillée dans le talus de l'aile nord de la Porte du Rebout (fig. 9 pour la localisation et fig. 22) est particulièrement révélatrice de l'adoption des nouvelles techniques pour les constructions de plan traditionnel. D'une surface de $14 \mathrm{~m}^{2}$, ses murs sont constitués de moellons irréguliers de rhyolite liés au mortier de chaux maigre. L'accès s'effectue par un escalier maçonné, 

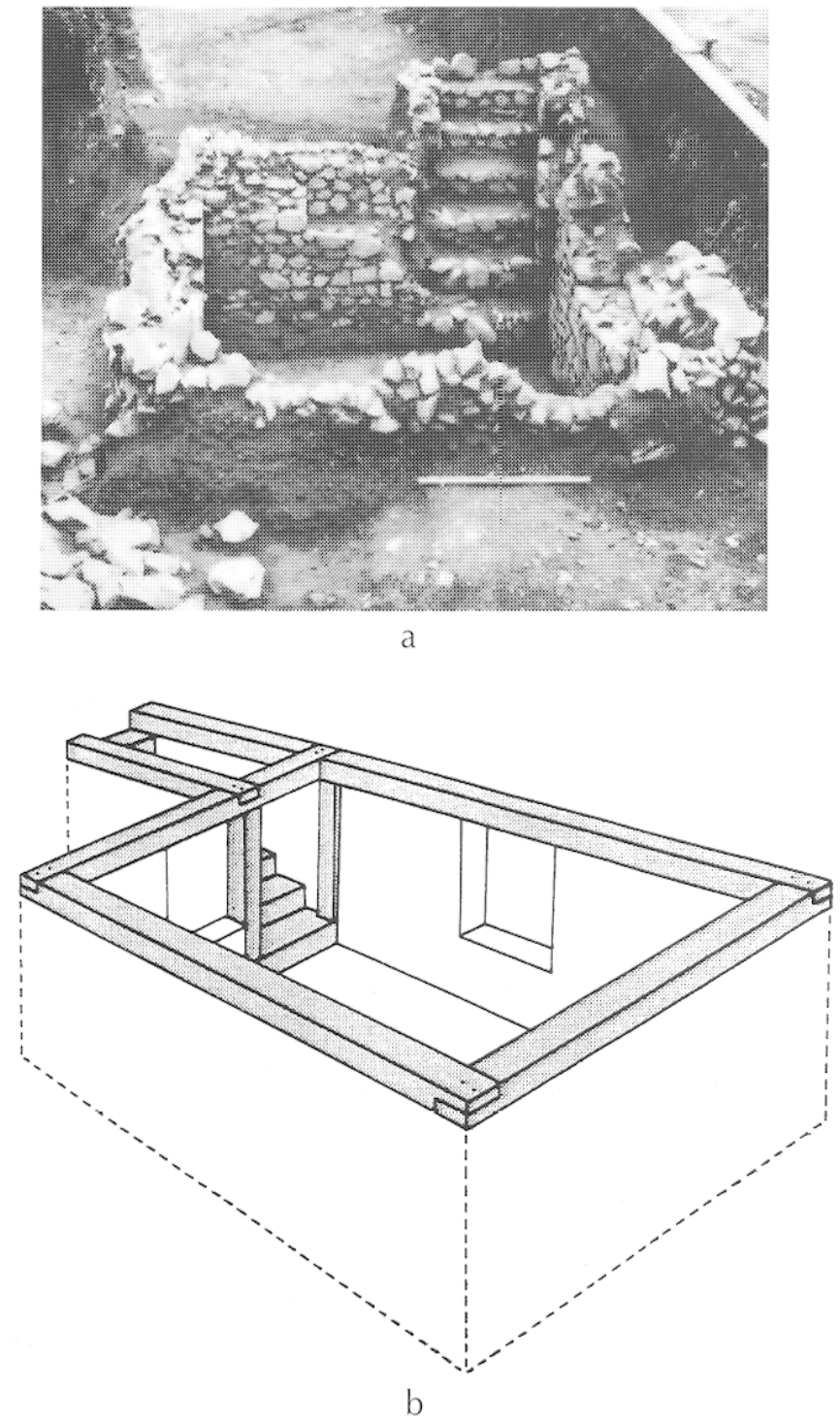

Fig. 22 - Cave installée dans les remblais du bastion septentrional de la Porte du Rebout : a, vue vers le sud (photo Bibracte/P. Barral); $b$, restitution.

habillé de bois dès l'origine. Deux niches larges de $85 \mathrm{~cm}$ et profondes de $35 \mathrm{~cm}$ sont aménagées dans les murs sud et ouest. De part et d'autre du seuil sont conservées les empreintes du chambranle de la porte qui servait également de soutien à la sablière haute portant les solives du plancher. L'arase des murs, à 2,10 $\mathrm{m}$ du sol, donne la hauteur minimale de la cave. Les couches de démolition contiennent des fragments de tegulae et d'imbrices qui indiquent la nature de la couverture.

En avant de la même Porte du Rebout, l'atelier de bronziers qui succède à une forge, est en relation avec une cave maçonnée fouillée par Bulliot (fig. 9). Ses murs, identiques à ceux de la cave située à l'arrière du rempart, étaient probablement couverts d'un enduit. La cage d'escalier, hors œuvre, n'est pas conservée ; seuls deux blocs de granite taillés constituant le seuil inférieur sont en place. À l'extérieur, un foyer à sole d'argile reposant sur un radier de tessons d'amphores, un mur maçonné reliant la paroi nord-est de la cave à celle de l'atelier, ainsi que quelques trous de poteau, démontrent la présence d'un espace couvert entre les deux bâtiments, d'usage probablement domestique. Quant à l'atelier lui-même, il est vraisemblablement constitué de parois en terre et bois, reposant sur des murets de pierre (fig. 33).

Au Champlain, des constructions fouillées par Bulliot ont été remises au jour en 1994 lors d'une campagne de sondages, notamment une autre cave du même type $\left(\mathrm{CP} 34^{\text {bis }}\right.$, aux murs de maçonnerie enduits de mortier de chaux. Son escalier d'accès est également maçonné, mais construit dans l'œuvre.

L'utilisation de ces trois caves s'inscrit dans une large fourchette de datation, la période augustéenne. Les résultats des fouilles de la Pâture du Couvent permettent une fois encore d'apprécier plus finement l'évolution des techniques de construction, grâce à un rythme rapide de réfection des bâtiments, régulièrement détruits par des incendies.

Une importante réorganisation de l'espace situé à l'ouest de la grande voie se produit dans les dernières décennies du $I^{\text {er }} s$. avant J.-C. Un nouveau bâtiment prend la place des précédents et s'accompagne de la création d'une cave (PCO 585, fig. 21b; mobilier étudié dans l'annexe I, p. 124) de taille remarquable et située dans une position privilégiée, en correspondance avec le front principal du bâtiment (fig. 13 et 21). Du bâtiment lui-même sont actuellement identifiées les limites nord et est, bordant un sol extérieur constitué de recharges successives de tessons d'amphores. Le rôle exact de ce pavement, situé en avant du bâtiment du côté du bassin et de la grande voie, devra être vérifié; pour l'instant son interprétation est celle d'un trottoir couvert par un portique soutenu par des poteaux en bois. Les limites sud et ouest du bâtiment restent pour le moment inconnues. La façade nord repose peut-être sur une sablière basse appuyée sur un mur de pierres liées par un mortier jaune. La façade est, quant à elle, armée par des poteaux équarris, comme dans l'état antérieur. La surface intérieure est maté- 


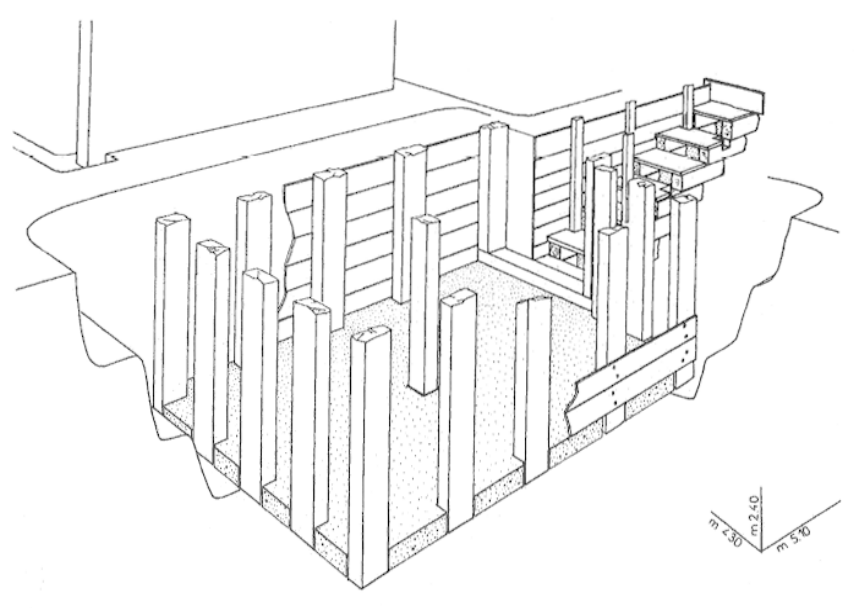

Fig. 23 - Reconstitution de la cave PCO 585 (dessin A. Zardini).

rialisée par des sols battus et parsemée de plusieurs foyers faits d'une chape d'argile installée sur un radier de tessons d'amphores. Elle est divisée par des cloisons dont subsiste l'empreinte des sablières basses. La cave $(5,5 \mathrm{~m} \times 4,0 \mathrm{~m})$, dont le boisage a été particulièrement bien conservé par l'incendie, est constituée d'un coffrage de planches horizontales calées par des poteaux verticaux équarris $(0,4 \mathrm{~m} \times 0,2 \mathrm{~m}$ ou $0,25 \mathrm{~m} \times 0,15 \mathrm{~m})$ répartis le long des parois (fig. 23). Ils soutenaient les sablières sur lesquelles étaient posés le plafond et le sol en terre de la pièce supérieure, épais d'environ $20 \mathrm{~cm}$. On y avait accès par l'extérieur du bâtiment, sur le côté ouest, au moyen d'un escalier en bois au bas duquel s'ouvrait une porte dont ont été retrouvées les charnières en fer. L'incendie qui détruisit entièrement le bâtiment a provoqué l'effondrement, dans le vide de la cave, des matériaux, soit céramiques, soit alimentaires, qui étaient conservés à l'étage. La carbonisation des éléments végétaux nous donne un aperçu des essences végétales utilisées dans les menuiseries (Chêne, Hêtre, Saule, Peuplier, Noisetier, Frêne) et des produits alimentaires stockés ( $c f$. infra, p. 63-65 et fig. 38).

De l'autre côté de la voie, sous la cave maçonnée PCO $2^{\text {is }}$, est apparue une structure excavée, partiellement fouillée, que l'on peut interpréter comme une cave plus ancienne. Un mur maçonné affaissé révèle la mise en ouvre de techniques de maçonnerie d'origine méditerranéenne. Une analyse dendrochronologique des bois carbonisés issus des couches de démolition fournit une

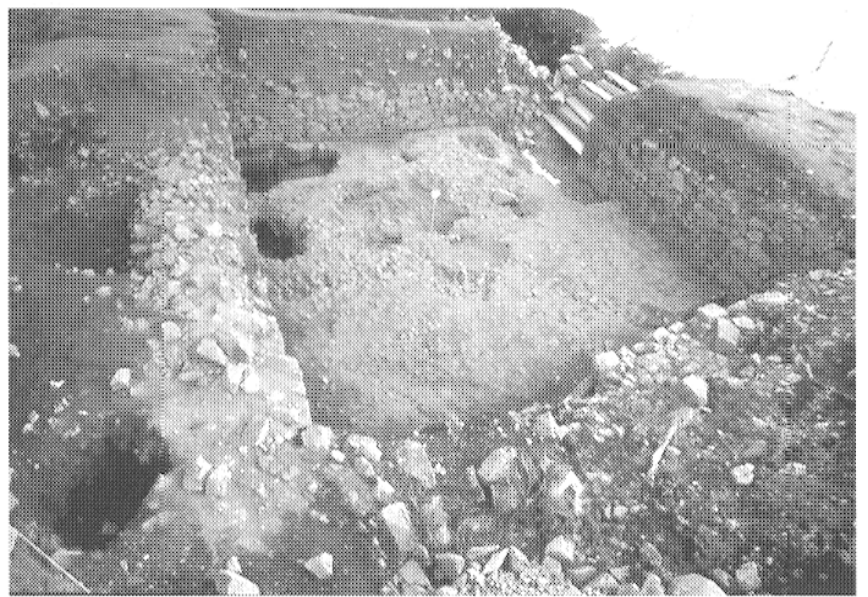

a

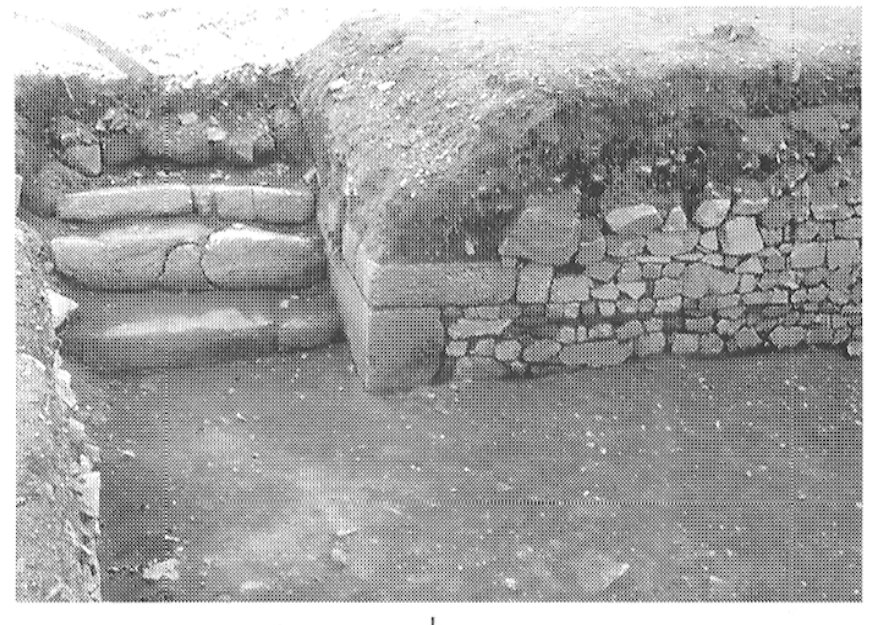

b

Fig. 24 - La cave PCO 2 : a, vue vers le nord-est; $b$, vue de détail de l'escalier.

date d'abattage de 17 avant J.-C. ${ }^{7}$. Le faciès du mobilier étudié jusqu'à présent est analogue à celui de la grande cave PCO 585 et date également l'abandon de la fin du $\mathrm{I}^{\mathrm{er}} \mathrm{s}$. avant J.-C. (Bonenfant, in : RF, 1995, 1).

Toujours à la Pâture du Couvent, la grande "maison à demi souterraine " maçonnée, fouillée par Déchelette en 1898 (PCO 2), qu'il pensait séparée en deux pièces (Déchelette, 1904, p. 22-26), s'avère être la juxtaposition de deux caves. La première, mesurant environ $39 \mathrm{~m}^{2}$, est munie d'un escalier externe à degrés de granite, large de $1,70 \mathrm{~m}$, ce qui indique peut-être une fonction de stockage de marchandises encombrantes (fig. 24). La

7. Mesure Archéolabs 1994, séquence 8004 BEU. 


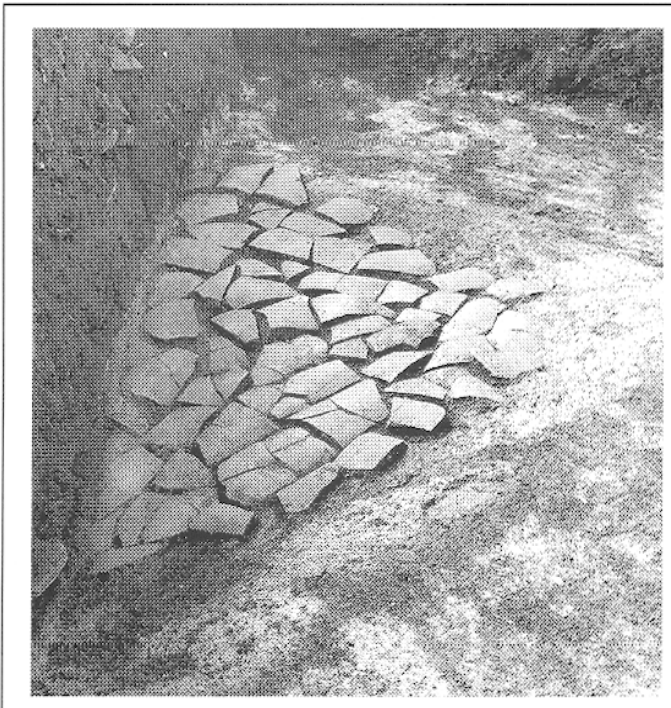

a

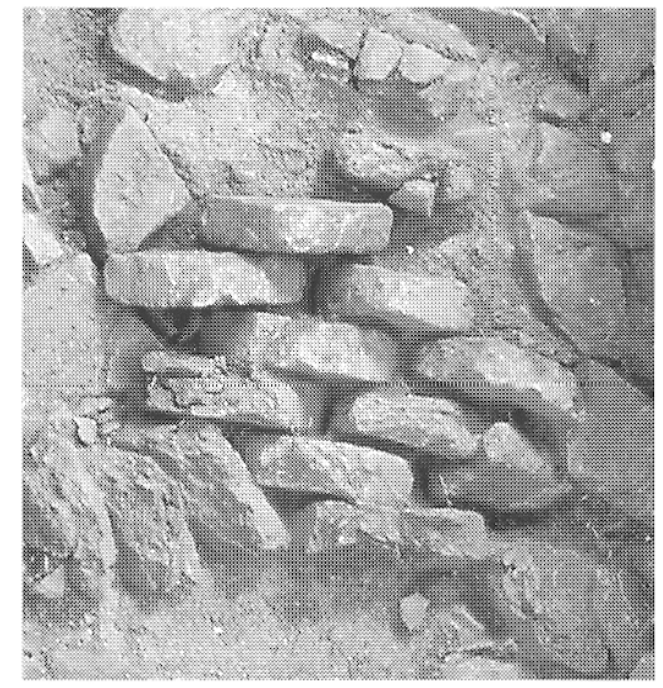

$\mathrm{C}$

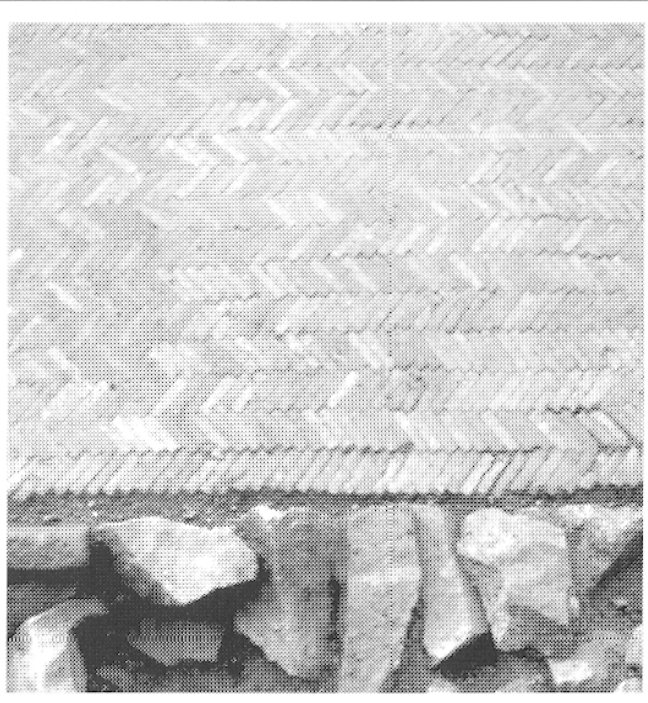

b
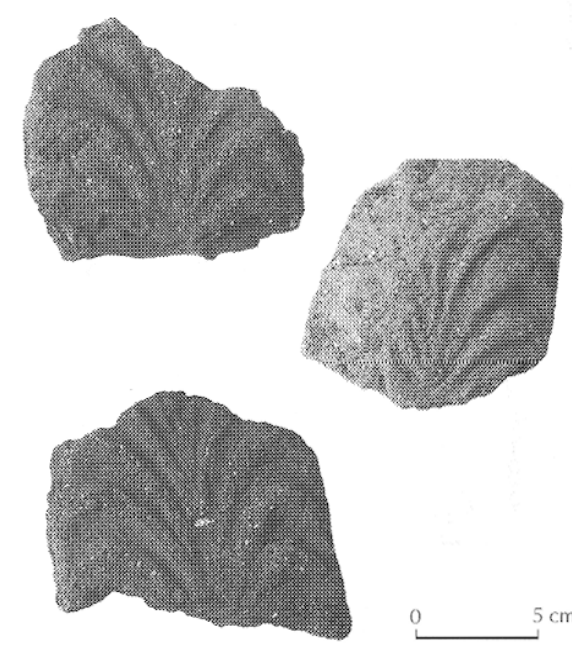

d
Fig. 25 - Matériaux

de construction et mise en cuvre de la terre cuite.

$a$, radier de foyer en amphore (Pâture du Couvent) ;

$b$, sol en opus spicatum (domus PC 1, état 4, Parc aux Chevaux); c, colonne effondrée (maison des Pierriers, Parc aux Chevaux) ; $d$, antéfixes (Pâture du Couvent). deuxième (PCO $2^{b i s}$ ), de $45 \mathrm{~m}^{2}$, possède un escalier dans l'œuvre, dont il ne reste que le mur d'échiftre. Leur identification à des caves ne fait aucun doute puisque leur hauteur sous plafond peut être restituée à au moins 1,7 m. La structure identifiée sous le sol de PCO $2^{\text {bis }}$ donne un terminus post quem de la fin du $\mathrm{I}^{\mathrm{er}}$ s. avant J.-C. pour la construction de celle-ci. Les fouilles récentes n'ont en revanche pas permis de préciser la forme et la nature des superstructures.

Environ $2 \mathrm{~m}$ plus au nord, se trouve une troisième cave maçonnée (PCO 3), de $26 \mathrm{~m}^{2}$, qui présente une entrée à l'est, large de 1,14 m. L'escalier, extérieur, est également en granite. Sa profondeur est au moins de
2,6 m. Son mur de façade nord-est se prolonge en direction de la grande voie. Il est donc probable que l'habitat correspondant se soit développé du côté ouest, recouvrant en partie, ou dans sa totalité, la cave en bois proche, alors comblée.

La romanisation se manifeste bien plus nettement encore par l'adoption d'un modèle architectural méditerranéen pour les maisons « aristocratiques » de plan plus développé. Si l'existence de ces maisons a été révélée par les fouilles du XIX ${ }^{e}$ s., seules les recherches récentes ont permis de préciser la date de leur apparition. Le sondage effectué sur le site de la vaste domus PC 1 a en effet révélé que celle-ci se superposait à une autre, 


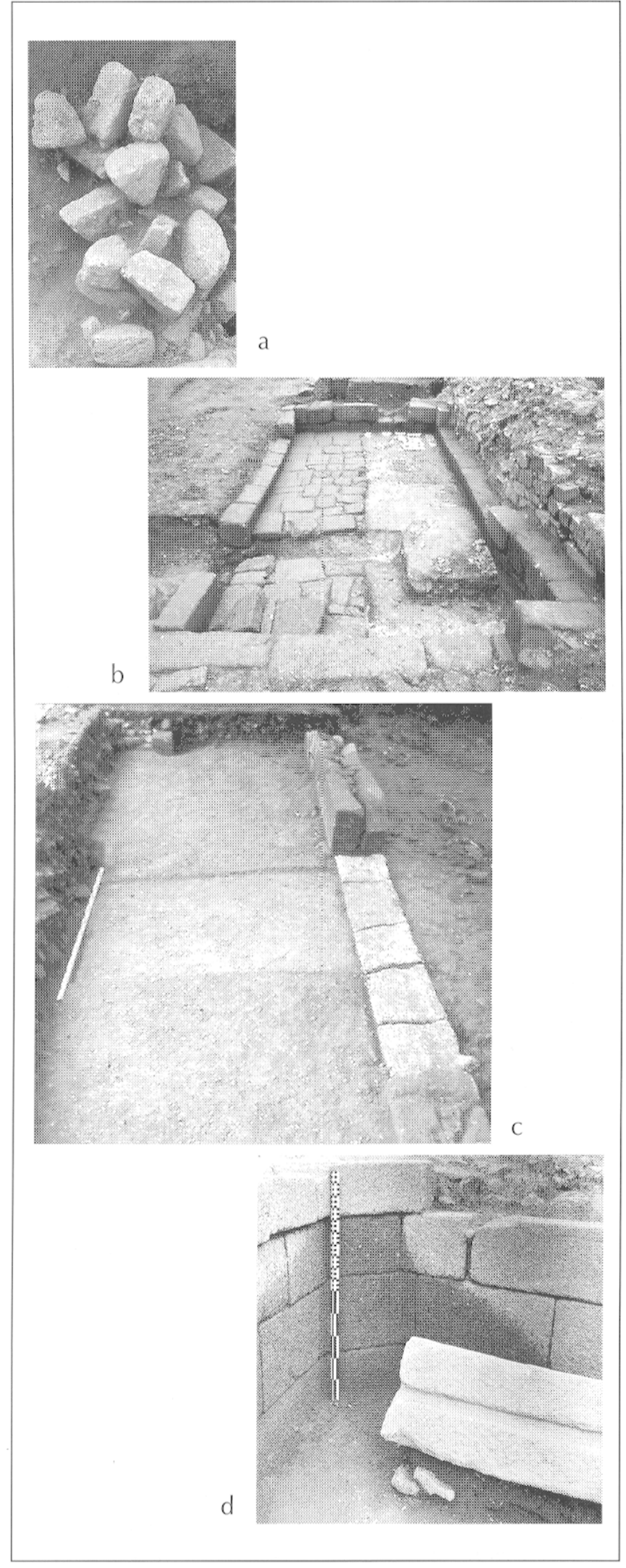

installée au début de l'époque augustéenne (état 4, cf. fig. 20). Bien que partiellement reconnue, cette dernière possède en effet toutes les caractéristiques de ce type d'habitat : plan symétrique organisé autour d'un atrium précédé d'un vestibule, collecte des eaux de pluie dans un impluvium et évacuation vers une citerne ; chauffage par hypocauste dans une pièce dont les parois sont revêtues de tegulae mammatae. Les matériaux et les techniques mises en œuvre sont également méditerranéens : emploi généralisé de la maçonnerie - qui utilise un liant de meilleure qualité - ; enduits muraux probablement peints ; toitures de tuiles ; sols dont la construction respecte à la lettre les préceptes vitruviens - tel celui de briquettes en terre cuite disposées en opus spicatum (fig. 25b) - ; utilisation du verre à vitre dans la pièce chauffée. Cependant les foyers et les fours culinaires, regroupés dans la même pièce, sont encore de type traditionnel : sole et superstructure d'argile sur radier de tessons d'amphores, auxquels on ajoute dès lors des fragments de tuiles et de briques.

Le dernier état de la domus PC 1 est l'exemple le plus élaboré des grandes maisons à atrium et péristyle fouillées par Bulliot (fig. 20). Nettement plus étendue que celle à laquelle elle succède, c'est l'une des plus grandes de Gaule puisqu'elle occupe une surface de $3800 \mathrm{~m}^{2}$. Les fouilles récentes suggèrent de dater sa construction de la deuxième décennie du $\mathrm{I}^{\mathrm{er}} \mathrm{s}$. après J.-C. Outre le développement considérable du plan, qui englobe maintenant cour intérieure et jardin à portique, les innovations principales, par rapport à la maison précédente, sont les changements apportés dans le système d'alimentation en eau. il consiste à capter une source jaillissant intra muros, puis à la canaliser au moyen d'aqueducs de facture classique vers un bassin en grand appareil de blocs de granite. De petits foyers faits de dalles de terre cuite posées sur le sol font leur apparition dans les pièces d'habitation de la maison, ainsi que des «foyers-cheminées " de type

Fig. 26 - Matériaux de construction el mise en auvre de la pierre de taille.

a, colonne effondrée en petit appareil de granite (îlot des Grandes Forges, Pâture du Couvent) ;

$b$, bassin en granite à l'angle nord de la domus PC 1 (état 5, Parc aux Chevaux) ;

c, seuil en calcaire du vestibule d'entrée de la domus PC 1 (état 5); $d$, détail de l'appareil de granite du bassin monumental de la Pâture du Couvent (photo Bibracte/P. Barral). 
gallo-romain. Dans la cuisine est construit un fourneau maçonné surélevé de type romain. Un petit ensemble balnéaire, avec caldarium et tepidarium, est installé dans l'angle nord-ouest de la domus, près de la cuisine. Dans celle-ci prenait place le praefurnium, qui comportait probablement un dispositif nécessaire au chauffage d'une cuve d'eau, de modèle semblable au système retrouvé dans le balnéaire du Parc aux Chevaux fouillé par Déchelette. Enfin, un portique longe le bâtiment du côté de la grande voie, à l'ouest.

Ce modèle architectural de type méditerranéen a probablement été aussi adopté à la Pâture du Couvent, dans l'îlot des Grandes Forges, quoique les fouilles ne soient pas encore assez avancées pour que l'on puisse en juger de façon définitive (fig. 13). On y a mis en évidence les éléments d'un grand bâtiment maçonné qui devait s'étendre jusqu'à la grande voie. La symétrie apparente de l'ensemble fait penser à une véritable domus (Szabó, in : RF, 1995, 1). Les quartiers de colonnes, les dalles et les pierres taillées, les terres cuites architecturales montrent l'importance des apports méditerranéens dans l'architecture de ce secteur de l'oppidum (fig. 26).

D. V., V. Z.

(Daniele Vitali, Véronique Zwald)

\section{LES NÉCROPOLES DE BIBRACTE}

\section{LA LOCALISATION DES SITES FUNÉRAIRES AUTOUR DU Mont Beuvray}

L'emplacement des nécropoles de l'agglomération antique était encore complètement ignoré il y a peu d'années jusqu'à la découverte inopinée du cimetière de la Croix du Rebout ( $c f$. infra). Si l'on exclut ce site, il nous reste divers indices pour localiser d'autres lieux funéraires, de valeur très inégale, toponymes évocateurs qui se rapportent probablement à des périodes plus récentes, ou allusions invérifiables d'érudits du XIX ${ }^{\mathrm{e}} \mathrm{s}$. ; nous les avons toutefois consignées systématiquement (fig. 27, $\mathrm{n}^{\text {os }}$ 7-12).

Rappelons aussi que Bulliot a régulièrement noté la découverte, au milieu des maisons de l'oppidum, d'ossements brûlés associés à des céramiques, qu'il identifiait à des tombes à incinération. Ces données, qui furent déjà mises en doute par Déchelette, ne doivent évidemment pas être retenues. Dans la même veine, on ne peut manquer de rester perplexe devant la mention par
Xavier Garenne (1867, p. 149-152) de milliers de tumulus funéraires, " alignés et aussi rapprochés que dans un cimetière ", sur la pente ouest du Mont Beuvray, le long des chemins qui mènent des Vieilles Maisons et du moulin de Malvaux aux Grandes Portes. Il dit encore en avoir fouillé plusieurs et y avoir trouvé des cendres... Toute cette zone, très en pente, est désormais plantée de résineux et l'on n'y voit aucune trace de tumulus, tandis qu'aucun mobilier archéologique significatif n'y a été trouvé en prospection.

Beaucoup plus prometteurs sont les sites repérés par prospection aérienne (fig. 27, $\mathrm{n}^{\text {os }} 1-6$ ). René Goguey a en effet bien identifié, dans un rayon de 4 à $8 \mathrm{~km}$ et dans un quart de cercle s'ouvrant au sud-ouest de Bibracte, six emplacements qui paraissent receler des sépultures protohistoriques. Même si aucun d'eux ne révèle en prospection terrestre des vestiges caractéristiques, leur nature (vastes enclos carrés) et leur localisation incitent à penser qu'il s'agit de tombes de grands propriétaires terriens, notamment si on les compare aux sépultures gauloises tardives du Luxembourg, comme celles de Lamadelaine ou de Clémency (Metzler et al., 1991).

\section{La nécropole de la Croix du Rebout}

La découverte d'une vaste nécropole en 1992, à l'occasion d'une fouille de sauvetage sur l'emplacement du futur musée de Bibracte, au pied nord-est du Mont Beuvray, a confirmé qu'il fallait chercher les cimetières de Bibracte à l'extérieur des remparts et le long des grandes voies d'accès. Le cimetière de la Croix du Rebout (fig. 28) se trouve en effet à l'emplacement d'un col $(613 \mathrm{~m})$ où convergeaient plusieurs routes venant de l'est et du nord-est, avant de pénétrer dans l'oppidum par la Porte du Rebout.

Exploré incomplètement sur une surface de 1,5 ha, ce cimetière à incinérations comprend 70 enclos funéraires quadrangulaires. Ces enclos, dont la taille varie de 3,5 à $11 \mathrm{~m}$ de côté, présentent généralement une entrée située à l'est. De vraisemblables ustrina semblent regroupés au sud, le long du chemin du Rebout (voie 3), principale voie d'accès antique à l'oppidum, large ici de $8 \mathrm{~m}$.

C'est seulement dans l'angle nord-est que la limite antique de la nécropole a peut-être été atteinte par la fouille. Des découvertes de mobilier en prospection de 


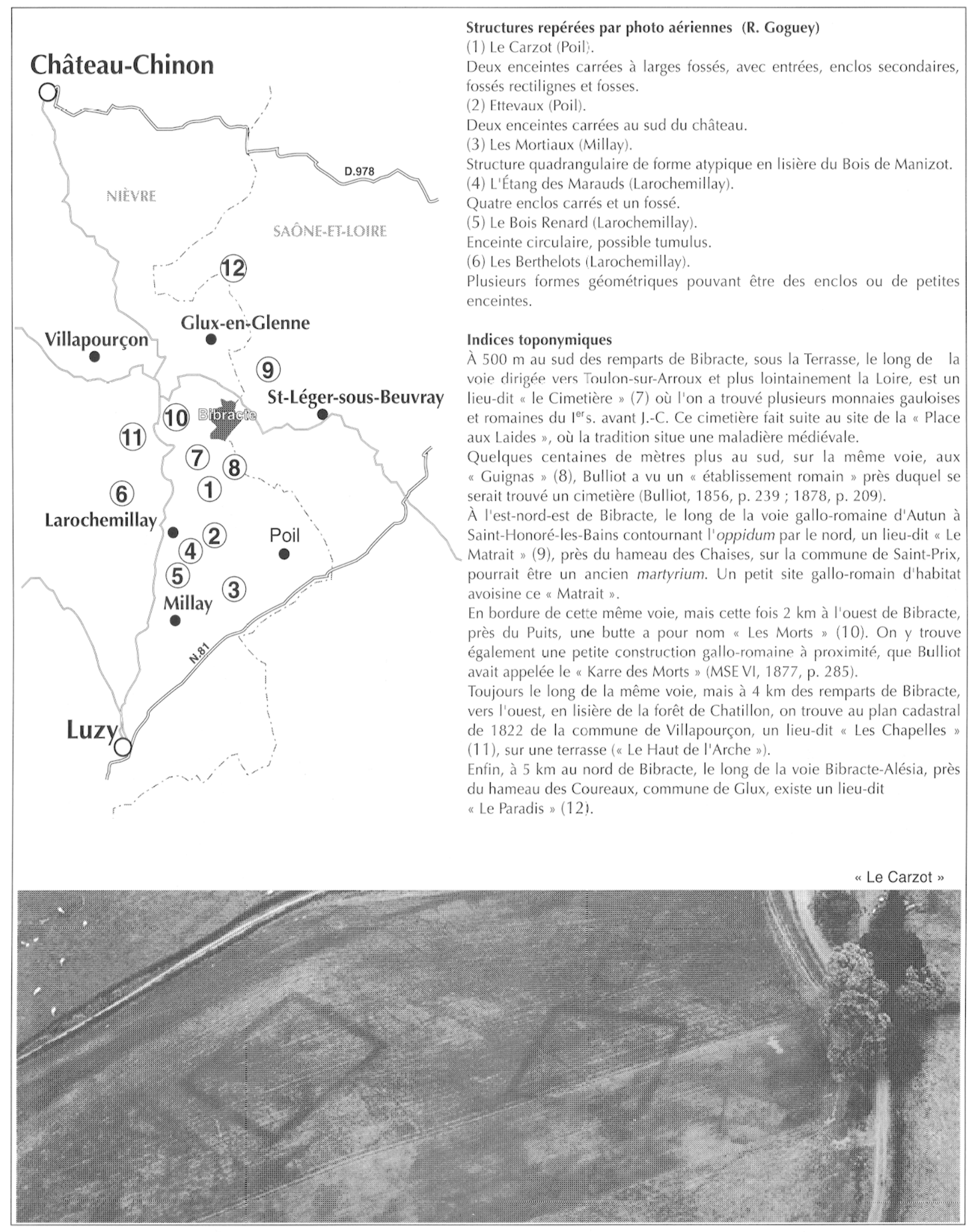

Fig. 27 - Carte de localisation des sites funéraires anciens présumés dans l'environnement du Mont Beuvray (photo R. Goguey). 


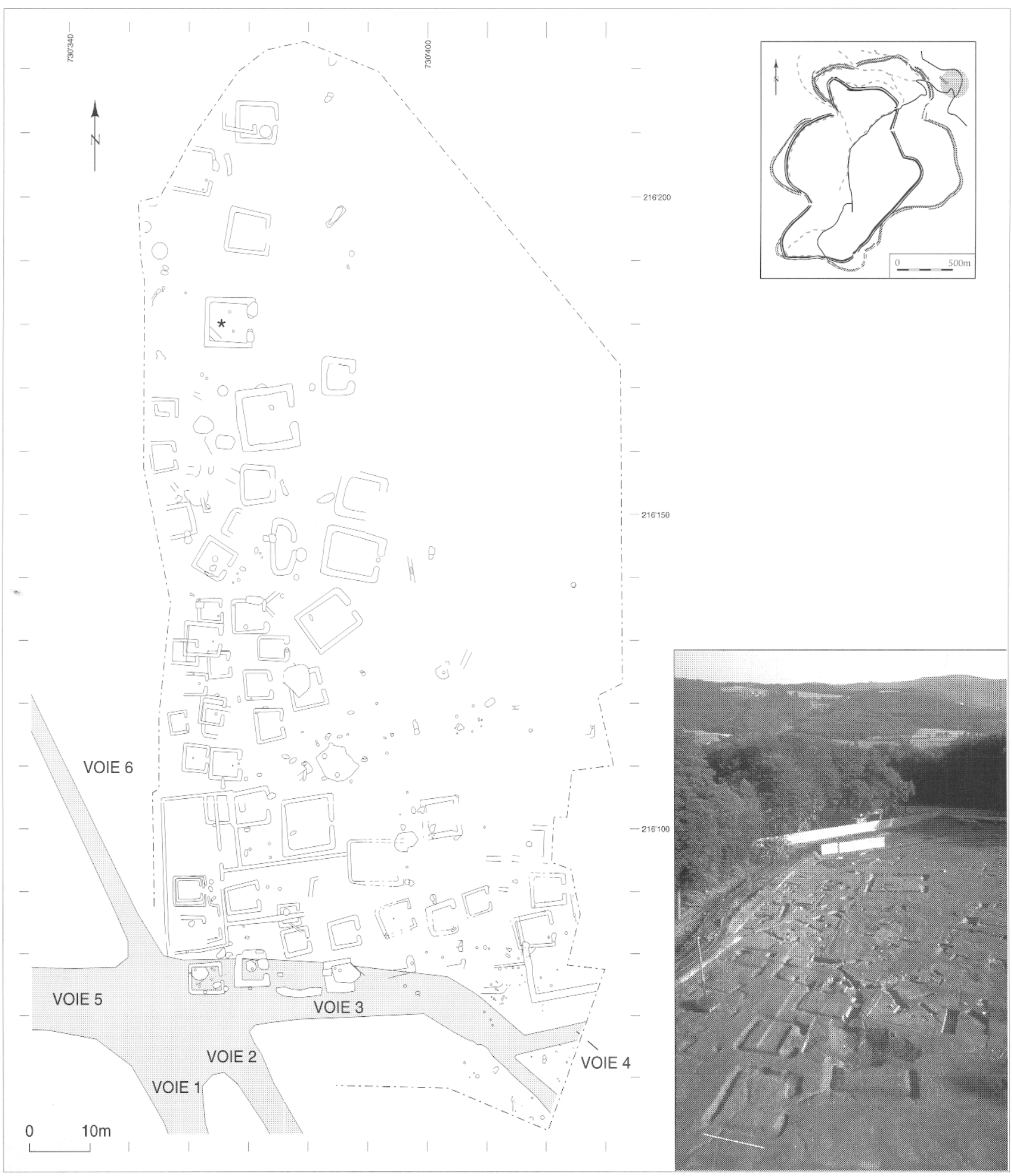

Fig. 28 - Plan et vue générale vers le nord du cimetière antique de la Croix du Rebout : *, enclos $n^{\circ} 49$. 


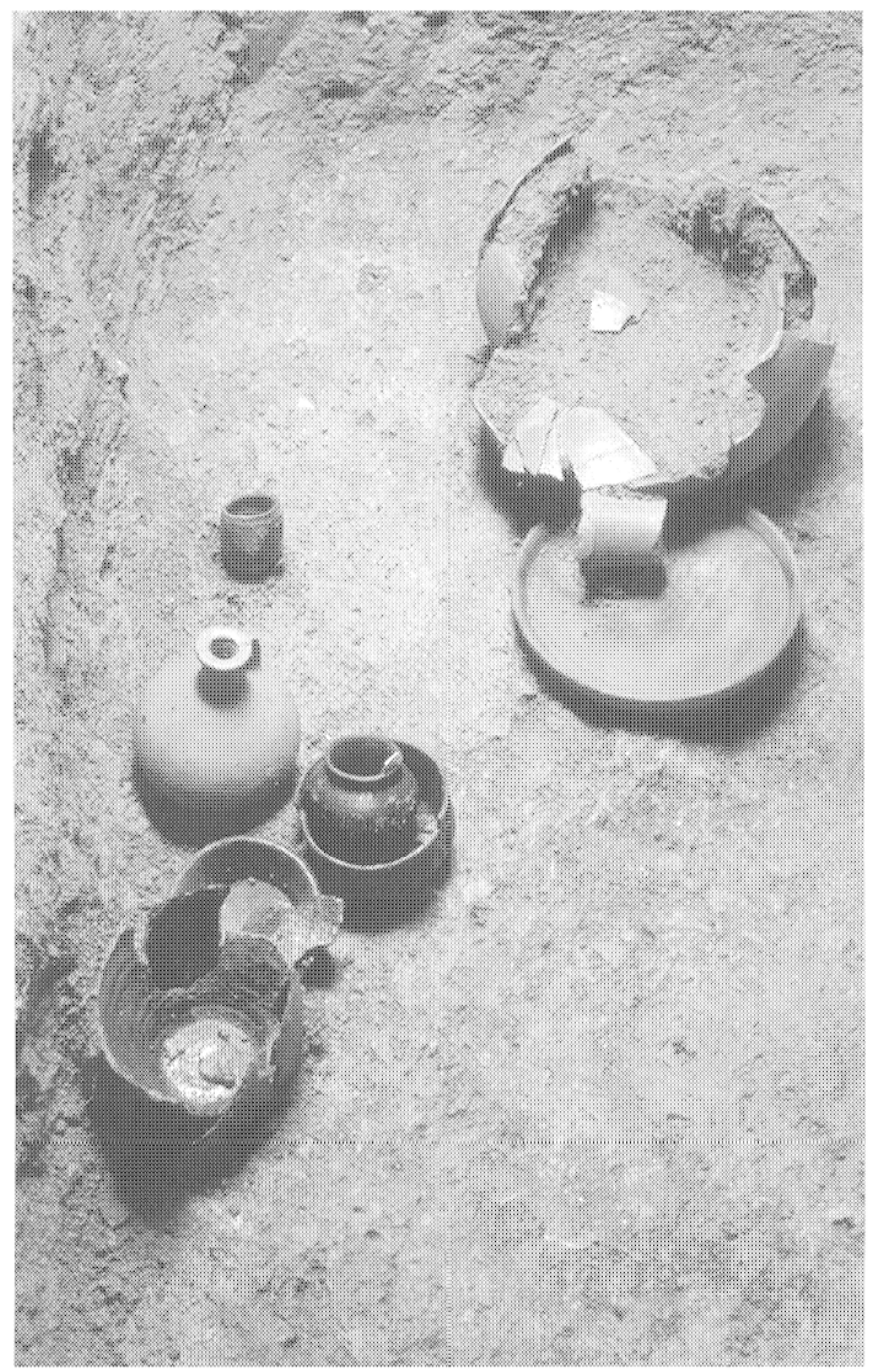

Fig. 29 - Un dépôt funéraire du cimetière de la Croix du Rebout in situ.

surface à $30 \mathrm{~m}$ à l'est de la fourche de la voie 3 , la présence d'enclos au sud, sous le nouveau tracé de la route départementale $\mathrm{D} 18$, déplacée à cette occasion, ainsi que probablement dans la coupe relevée lors de la construction du mur ouest du musée, suggèrent une extension plus importante de la nécropole que ce que l'on en connaît réellement. Le réseau de voies antiques, notamment au sud, le long du chemin du Rebout, a manifestement joué un rôle structurant, du moins dans sa phase ancienne. Par la suite, on constate l'empiétement des enclos sur l'espace de cette voie et sur celui d'une autre située $30 \mathrm{~m}$ au sud (voie 2 ). On peut supposer que l'agglomération d'enclos observée sur le bord ouest de la fouille correspond également à la présence d'une voie nord-sud, dont un tronçon a été découvert sur le bord est de l'ancienne route départementale.

Dans l'ensemble, la gestion des parcelles attribuées aux défunts, qui semblent parfois réunir des groupements familiaux (?), aurait été bien organisée puisque sept enclos seulement sont venus perturber des structures funéraires antérieures. Aucune trace de construction à plusieurs poteaux n'a été reconnue à l'intérieur de ces enclos ; en revanche des poteaux isolés, dans le fossé ou sur la plate-forme, correspondent peut-être à une signalisation des structures funéraires, voire à des tombes. Les fossés semblent le plus souvent avoir été recomblés aussitôt après leur creusement.

Les travaux agricoles sont vraisemblablement à l'origine de la disparition de la plupart des tombes que circonscrivaient les enclos. En effet, sur la quarantaine de tombes découvertes, 13 seulement se trouvaient à l'intérieur des 70 enclos; les autres étaient isolées. D’apparence généralement peu spectaculaire, elles se présentent sous deux formes : soit les ossements incinérés sont contenus dans un vase dont le type et l'état de conservation sont très variables, soit le dépôt d'ossements est posé sur le fond de la fosse, puis est recouvert par quelques tessons.

Outre les tombes proprement dites, des dépôts secondaires, $46 \mathrm{au}$ total, qui ne présentent pas d'ossements, sont le plus souvent constitués d'une association de vases à boire et à nourriture (de 1 à 9 vases) (fig. 29). Ils ont été découverts un peu partout sur le site avec, tout de même, une relative fréquence devant les entrées des enclos.

D'autres structures, apparemment sans rapport avec la nécropole, se trouvaient également au milieu des tombes. Il s'agit d'une quinzaine de fours et de foyers, dont certains bien construits, présentant une sole circulaire de 0,6 à $1,2 \mathrm{~m}$ et une fosse à cendres. Ces structures, probablement d'usage domestique, appartiennent à une phase d'occupation légèrement postérieure au cimetière. Enfin sur la grande voie 3 , au sud, a été repérée une structure particulière, constituée d'une levée de terre renforcée par un système de deux grosses sablières parallèles encadrées de larges poteaux.

L'étude du mobilier céramique (fig. 30), rendue difficile dans le cas des tombes par la pratique de dépôt sur le bûcher, a néanmoins montré que les vases de service étaient plus nombreux que les vases à usage culinaire (70\% contre $30 \%$ ). Les formes basses sont : écuelles, 


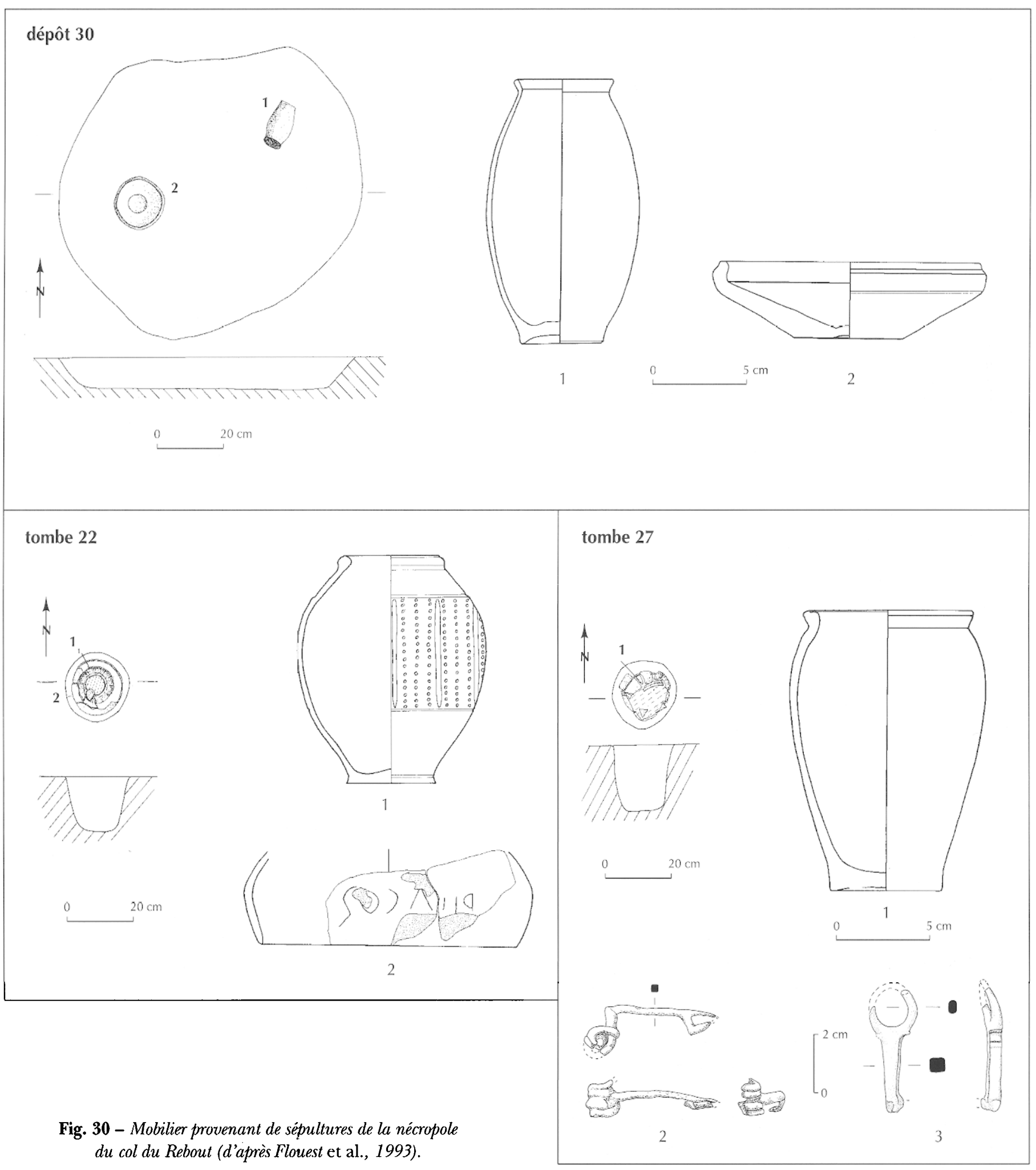


jattes à rebord mouluré, marmites tripodes pour les catégories en céramique grossière ; assiette imitant la forme Lamb. $5 / 7$ pour les catégories en céramique fine. Les formes hautes sont : pots à bord évasé plus ou moins mouluré en céramique grossière; tonnelets, vases bobines, gobelets, pots à col court souligné par une baguette, en céramique fine.

Outre les éléments métalliques des coffrages en bois de certaines tombes, ont été retrouvés des éléments de parure, notamment 69 fibules - filiformes, de type Nauheim ou à queue de paon - qui ont pu être identifiées malgré leur passage quasi systématique sur le bûcher et les dégradations inhérentes à cette pratique (fig. 30). Quelques pièces d'armement sont également à signaler : fragments d'umbo de bouclier, de fourreau d'épée, ainsi que deux pointes de lance. Si ces derniers éléments, ainsi que quelques autres assimilables à des outils, peuvent suggérer des tombes d'adultes, les résultats de l'analyse anthropologique (étude encore inédite de M.-A. Porro) montrent que, sur la quarantaine de tombes, vingt correspondent à des sujets de moins de 18 ans, deux appartiennent à des adultes, tandis que les autres dépôts contiennent des restes dont on ne peut rien préciser. L'analyse des ossements trouvés sur les bûchers ou dans les rejets de bûchers, quand elle était possible, a confirmé cette omniprésence d'individus jeunes. Cinq cas d'ossements animaux ont été également relevés.

Cette nécropole recèle manifestement une proportion importante de jeunes individus de condition sociale sans doute modeste, disposés selon un rituel tout à fait habituel en milieu gaulois au $\mathrm{I}^{\mathrm{er}} \mathrm{s}$. avant J.-C. La découverte d'autres tombes, voire d'autres cimetières associés à l'oppidum, en particulier pour des périodes plus anciennes, serait un élément précieux pour l'étude de la population de l'oppidum et son évolution.

J.-L. F., R. N., D. Q.

(Jean-Loup Flouest, Roland Niaux, Dean Quinn)

\section{L'OPPIDUM, LIEU DE PRODUCTION ET D'ÉCHANGES}

On définit généralement l'oppidum comme une place centrale fortifiée aux fonctions politiques, religieuses et économiques. L'aspect politique est toujours difficile à apprécier, mais l'ampleur des fortifications et leur rôle autant ostentatoire que défensif confirment l'importance de Bibracte, "oppidum apud Haeduos maximae auctoritatis " aux dires de César. L'existence de vastes demeures semble bien indiquer qu'une partie de l'élite éduenne y résidait, au moins dans les décennies postérieures à la conquête. La présence de plusieurs sanctuaires ou lieux de rassemblement y est fortement présumée. Mais, surtout, l'archéologie montre que l'oppidum est le lieu d'une intense activité économique.

L'usage grandissant de l'écriture et de la monnaie est un traceur indiscutable de la spécialisation des tâches et du développement des transactions commerciales. Le Mont Beuvray est sans doute l'oppidum qui a livré le plus grand nombre de traces d'activités artisanales, en particulier celles liées aux arts du feu (métallurgie du fer et des alliages de cuivre, émaillerie), qui laissent des vestiges facilement repérables et parfois conservés de façon spectaculaire, comme c'est le cas des ateliers fouillés ces dernières années à la Porte du Rebout ( $c f$. infra, p. 52). On y a aussi frappé et coulé monnaie. Manquent en revanche des ateliers de potiers, bien que les analyses typologiques et physico-chimiques tendent à individualiser une production microrégionale. Peut-être faut-il les rechercher plutôt à l'extérieur de l'oppidum, plus près des sources d'approvisionnement en bois qui est la matière première la plus pondéreuse requise par cet artisanat. La circulation de denrées de toutes sortes et de provenances diverses est une réalité dès avant la fin du $\mathrm{II}^{\mathrm{e}} \mathrm{s}$. avant J.-C. ; Bibracte apparaît à la fois comme un centre de production et de redistribution des marchandises tant locales que méditerranéennes.

Les lieux dévolus à la métallurgie sont faciles à repérer. Bulliot et Déchelette ont suggéré qu'ils étaient confinés dans certains secteurs de l'oppidum, en particulier le long de la grande voie issue de la Porte du Rebout (fig. 2). S'il est clair que ce genre d'activité était exclu dans les grandes maisons tardives du Parc aux Chevaux, les recherches récentes montrent en fait que les résidus métallurgiques sont, ce cas particulier mis à part, pratiquement omniprésents sur l'oppidum. Les lieux du commerce sont en revanche plus difficiles à identifier. Les recherches récentes n'ont pu repérer aucun espace réservé aux transactions. Bulliot propose quant à lui plusieurs emplacements pour ces derniers, sans qu'il soit aujourd'hui possible de vérifier ses intuitions : les « loges » de la Chaume, le «bazar » de la Côme Chaudron. La localisation d'un marché sur la Chaume 